\title{
The pH Response and Sensing Mechanism of n-Type $\mathrm{ZnO/Electrolyte} \mathrm{Interfaces}$
}

\section{Safaa Al-Hilli * and Magnus Willander}

Department of Science and Technology, Campus Norrköping, Linköping University, SE-60174

Norrköping, Sweden; E-Mail: Magnus.Willander@itn.liu.se

* Author to whom correspondence should be addressed; E-Mail: Safaa.Al-Hilli@itn.liu.se; Tel.: +46-11-363-377; Fax: +46-11-363-270.

Received: 26 August 2009 / Accepted: 9 September 2009 / Published: 16 September 2009

\begin{abstract}
Ever since the discovery of the $\mathrm{pH}$-sensing properties of $\mathrm{ZnO}$ crystals, researchers have been exploring their potential in electrochemical applications. The recent expansion and availability of chemical modification methods has made it possible to generate a new class of electrochemically active $\mathrm{ZnO}$ nanorods. This reduction in size of $\mathrm{ZnO}$ (to a nanocrystalline form) using new growth techniques is essentially an example of the nanotechnology fabrication principle. The availability of these $\mathrm{ZnO}$ nanorods opens up an entire new and exciting research direction in the field of electrochemical sensing. This review covers the latest advances and mechanism of $\mathrm{pH}$-sensing using $\mathrm{ZnO}$ nanorods, with an emphasis on the nano-interface mechanism. We discuss methods for calculating the effect of surface states on $\mathrm{pH}$-sensing at a $\mathrm{ZnO} /$ electrolyte interface. All of these current research topics aim to explain the mechanism of $\mathrm{pH}$-sensing using a $\mathrm{ZnO}$ bulk- or nano-scale single crystal. An important goal of these investigations is the translation of these nanotechnology-modified nanorods into potential novel applications.
\end{abstract}

Keywords: $\mathrm{ZnO}$ nanorods; $\mathrm{pH}$ sensor; electrolyte double layer; n-type $\mathrm{ZnO}$-electrolyte interface; fermi level pinning; potentiometric measurements 


\section{Introduction}

In the study of electrochemistry the electrode was used for a long time only as a source, or a sink, of electrons provided by an electronic conductor with low resistivity. This paradigm has changed, largely due to the interest shown by electrochemists in the field of metal oxide semiconductors.

In contrast to metal electrodes, metal oxide semiconductor electrodes are well-suited to address some of the fundamental predictions of interfacial electron transfer theories. An ideal semiconductor has no electronic levels in the band gap region; therefore, for an n-type material, only electrons with energies near the conduction band can contribute to the cathodic interfacial current flow.

Unlike in a metal electrode, the driving force at a semiconductor electrode cannot be changed by varying the potential of the electrode. This situation occurs because the differential capacitance of a non-degenerately doped semiconductor electrode is much smaller than the differential capacitance of the electrolyte. Essentially all of the applied potential drops across the electrode and not across the electrolyte. Hence, the only methods of changing the driving force are to vary the energetics of the redox species in the solution, or to vary the identity or chemical state of the semiconductor surface.

$\mathrm{ZnO}$ is a material of interest in fundamental studies of the semiconductor/electrolyte (SC/EL) interface. $\mathrm{ZnO}$ also has practical applications in transparent conducting electrodes, sensors, and topical medical pastes that take advantage of its UV-induced generation of peroxide species, which act as sterilizing agents. $\mathrm{ZnO}$ nanorods can act as charge collecting electrodes in dye-sensitized photo-electrochemical cells. Many of these applications are based on electrochemical reactions at the $\mathrm{ZnO}$ surface, which involve free carriers.

Semiconductor problems have also stimulated many physicists to probe electrochemical questions. In this paper, we discuss several areas in which $\mathrm{ZnO}$ semiconductors have offered new perspectives on electrochemistry. For this discussion, we have chosen the principal areas listed below.

1. Energy levels in semiconductors and electrolytes

2. The electrical double layer

3. Mapping of the semiconductor band edge positions relative to solution redox levels ( $\mathrm{pH}$-sensing).

4. The role of surface states.

We will, in the present paper, look at the distributions of charge, potential, and capacitance at the zinc oxide-electrolyte interface. The distinction between metal and semiconductor electrodes is important when we consider the electrostatics across the corresponding solid-liquid interfaces.

\section{Energy Levels in Semiconductors and Liquids}

\subsection{Electron Energy Levels in Semiconductors and the Energy Band Model}

The quantum theory of solids presents a complete description of the energy levels in a semiconductor, the nature of charge carriers, and laws governing their motion [1,2]. The filled energy states correspond to the valence band (its upper edge is denoted as $E_{\mathrm{v}}$ ) and the empty states to the conduction band (its lower edge is denoted $E_{\mathrm{c}}$ ). The energy bands are separated by the band gap, $E_{\mathrm{g}}$, as illustrated in Figure 1a. In solid state physics, the vacuum level is taken as the zero energy reference. 
The density of energy states within the energy bands increases with the square root of energy above the conduction band or below the valence band edge and is given by:

$$
N_{C}=\frac{8 \sqrt{2 \pi}}{h^{3}}\left(m_{e}^{*}\right)^{\frac{3}{2}}\left(E-E_{c}\right)^{\frac{1}{2}}
$$

for the conduction band and:

$$
N_{C}=\frac{8 \sqrt{2 \pi}}{h^{3}}\left(m_{h}^{*}\right)^{\frac{3}{2}}\left(E-E_{V}\right)^{\frac{1}{2}}
$$

for the valence band, in which $h$ is Planck's constant and $m_{\mathrm{e}}{ }^{*}$ and $m_{\mathrm{h}}{ }^{*}$ are the effective masses of electrons and holes, respectively. The electron and hole densities in the conduction and valence bands, respectively, are related to the corresponding Fermi levels, $E_{\mathrm{F}, n}$ and $E_{\mathrm{F}, p}$, by:

$$
\begin{aligned}
& n=N_{c} \exp \left(-\frac{E_{c}-E_{F, n}}{k T}\right) \\
& p=N_{V} \exp \left(-\frac{E_{V}-E_{F, p}}{k T}\right)
\end{aligned}
$$

in which $N_{\mathrm{c}}$ and $N_{\mathrm{v}}$ are given by Equations (1) and (2). At equilibrium, the Fermi levels of electrons and holes are identical, i.e., $E_{\mathrm{F}, n}=E_{\mathrm{F}, p}=E_{\mathrm{F}}, n=n_{0}$, and $p=p_{0}$. Inserting these values into Equations (3) and (4) and multiplying these two Equations, one obtains, at equilibrium:

$$
n_{i}^{2}=n_{o} p_{o}=N_{C} N_{V} \exp \left(\frac{E_{C}-E_{V}}{k T}\right)=N_{C} N_{V} \exp \left(-\frac{E_{g}}{k T}\right)
$$

where $n_{i}^{2}$ is a material constant which decreases exponentially with increasing band gap, $\mathrm{E}_{\mathrm{g}}$. The relative position of the Fermi level, $E_{\mathrm{F}}$, depends on the electron and hole concentration, i.e., on the doping of the semiconductor. The equilibrium carrier densities in the conduction and valence bands, $n_{0}$ and $p_{0}$, can be calculated using Equations (3) and (4). Typical carrier densities in semiconductors range from $10^{15}$ to $10^{19} \mathrm{~cm}^{-3}$. This level corresponds to a range of Fermi levels, $E_{\mathrm{F}}$, of $0.04-0.25 \mathrm{eV}$ with respect to one of the energy bands. Thus, only a small portion of the energy states at the edges are occupied.

\subsection{Solution-Redox Levels}

Considerations of interfacial electron transfer require knowledge of the relative positions of the participating energy levels in the two phases (semiconductor and solution). Besides the Fermi level of the redox system, this model introduces the existence of occupied and empty energy states corresponding, respectively, to the reduced and oxidized species of the redox system. The model leads to a Gaussian distribution of redox states versus electron energy, as illustrated in the Figure 1b. The distribution functions for the states are given by [3]:

$$
D_{o x}=\exp \left[-\frac{\left(E-E_{F, r e d o x}-\lambda\right)^{2}}{4 k T \lambda}\right]
$$




$$
D_{\text {red }}=\exp \left[-\frac{\left(E-E_{F, \text { redox }}+\lambda\right)^{2}}{4 k T \lambda}\right]
$$

in which $\lambda$ is the well-known reorganization energy of electron transfer theory [4]. Generally, $\lambda$ falls in the range of $0.5-2 \mathrm{eV}$, depending on the interaction of the redox molecule with the solvent. The Gaussian type of distribution is a consequence of the assumption that the fluctuation of the solvation shell corresponds to a harmonic oscillation. Models for redox energy levels in solution have been exhaustively treated in several articles [3,5-10].

Figure 1. Energy levels in (a) a semiconductor and (b) a redox electrolyte, shown with a common vacuum reference scale, where $\chi$ and $\varphi$ are the semiconductor electron affinity and work function, respectively.

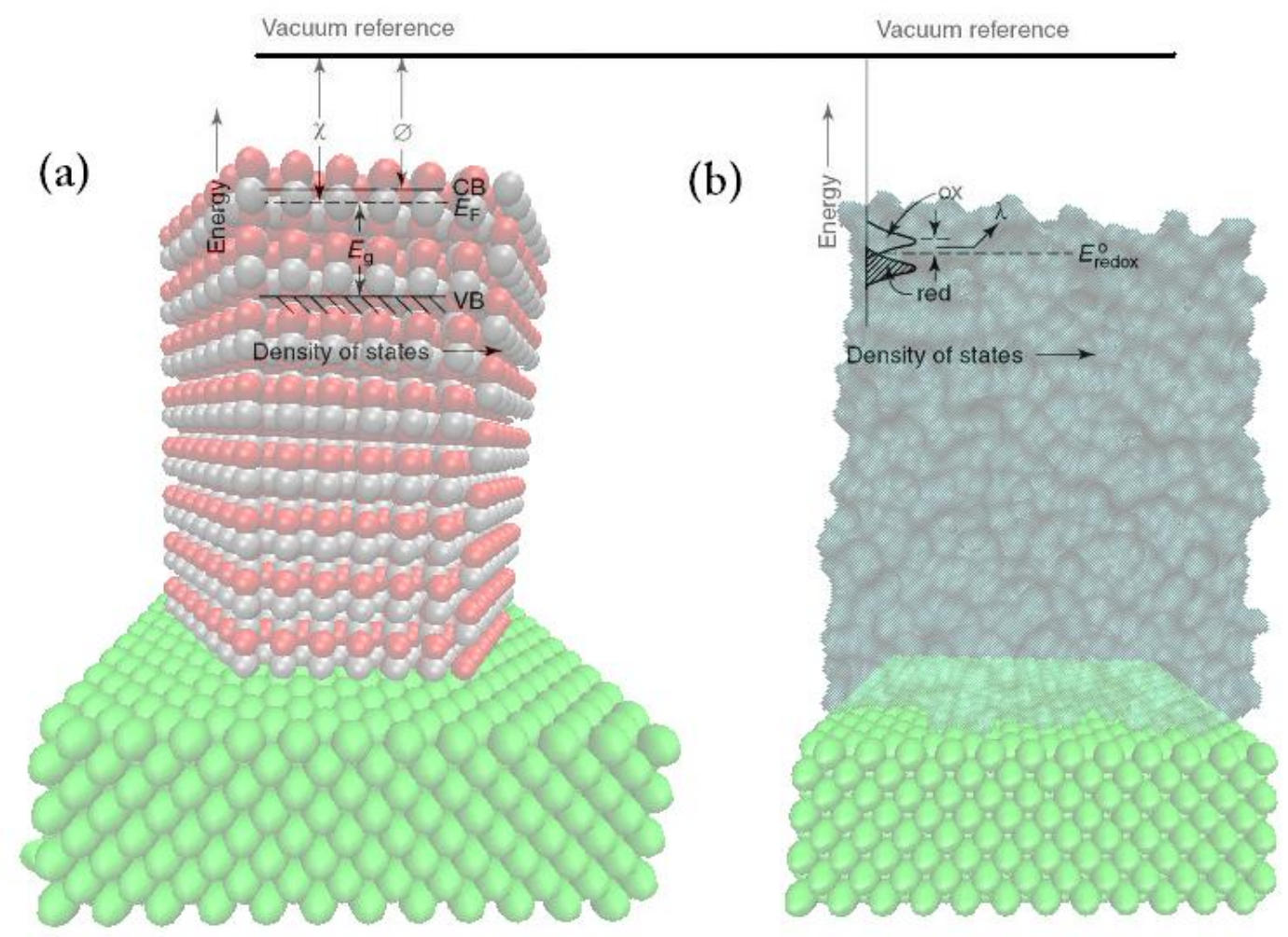

\section{3. n-Type Semiconductor-Electrolyte Systems at Equilibrium}

It should be emphasized that the Fermi level is actually the electrochemical potential of electrons in the solid. The electrochemical potential of electrons in a redox electrolyte is given by the Nernst expression:

$$
E_{\text {redox }}=E_{\text {redox }}^{o}+\frac{R T}{n F} \ln \left\lfloor\frac{c_{o x}}{c_{\text {red }}}\right\rfloor
$$

or:

$$
\bar{\mu}_{e, r e d o x}=\mu_{r e d o x}^{o}+k T \ln \left(\frac{c_{o x}}{c_{r e d}}\right)
$$


in which $c_{\text {ox }}$ and $c_{\text {red }}$ are the concentrations (roughly equal to the activities) of the oxidized and reduced species of the redox couple system, respectively. The parameter $E_{\text {redox }}=\mu_{e, \text { redox }}$ can be equated to the Fermi level $E_{F, \text { redox }}$ in the electrolyte. In this case, the electrochemical potential of electrons in a redox system is equivalent to the Fermi level, $E_{F, \text { redox }}$; i.e.,:

$$
E_{F, \text { redox }}=\bar{\mu}_{e, \text { redox }}
$$

on the absolute scale [9]. The task now is to relate the electron energy levels in the solid and liquid phases on a common basis.

In semiconductor solid-state physics, the vacuum level has been adopted as the standard reference. In contrast, electrochemists express redox potentials on a conventional scale, using the normal hydrogen electrode (NHE) or the saturated calomel electrode (SCE) as a reference point. The electrochemical potential of a redox system is usually given with respect to the normal hydrogen electrode (NHE). Using an absolute energy scale, the energy of a redox couple is given by [11]:

$$
E_{E, \text { redox }}=E_{\text {ref }}-q V_{\text {redox }}
$$

in which $\mathrm{V}_{\text {redox }}$ is the redox potential vs NHE, and $E_{\text {ref }}$ is the energy of the reference electrode versus the vacuum level. The determination of $E_{\text {ref }}$ has been the subject of several calculations [12,13]. The values derived by various authors range from 4.3 to $4.7 \mathrm{eV}$. Usually, an average value of $E_{\text {ref }}=4.5 \mathrm{eV}$ for NHE is used, so that Equation 11 yields:

$$
E_{F, \text { redox }}=-4.5-q V_{\text {redox }}
$$

with respect to the vacuum level. The relationship between the various energy scales for the solid and liquid phases is shown in Figure $1 b$.

When a semiconductor is immersed in a redox electrolyte, the electrochemical potential is disparate across the interface. In order for the two phases to be in equilibrium, their electrochemical potential must be the same. The electrochemical potential of the solution is determined by the redox potential of the electrolyte species, and the redox potential of the semiconductor is determined by its Fermi level. A movement of charge between the semiconductor and the solution is required to equilibrate the two phases if their redox potentials (Fermi levels) do not lie at the same energy. The excess charge that is now located on the semiconductor does not lie at the surface, as it would for a metallic electrode but extends into the electrode for a significant distance. This region is referred to as the space charge region and has an associated electric field.

For an n-type semiconductor electrode at open circuit, the Fermi level is typically higher than the redox potential of the electrolyte. Electrons will therefore be transferred from the electrode into the solution. There is thus a positive charge associated with the space charge region, and this is reflected in an upward bending of the band edges by an energy of $\mathrm{V}_{\mathrm{sc}}$, which depends on the doping (see Figure 2). Since the majority charge carrier of the semiconductor has been removed from this region, this region is also referred as the depletion layer. After contact, the Fermi levels of the semiconductor and the redox system must be equal on both sides of the interface [14]:

$$
E_{F}=E_{F, r e d o x}
$$

and a built in-voltage, $\mathrm{V}_{\mathrm{sc}}$, develops within the semiconductor phase. 
Figure 2. Energy levels of n-type $\mathrm{ZnO}$ before equilibrium (a) and the band bending in n-type $\mathrm{ZnO}$ electrode upon equilibration of the Fermi level of the semiconductor with the redox species (b).

(a)

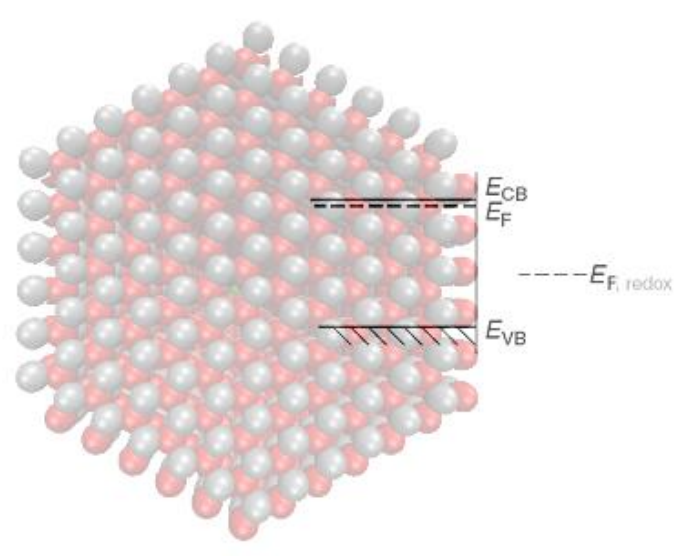

(b)

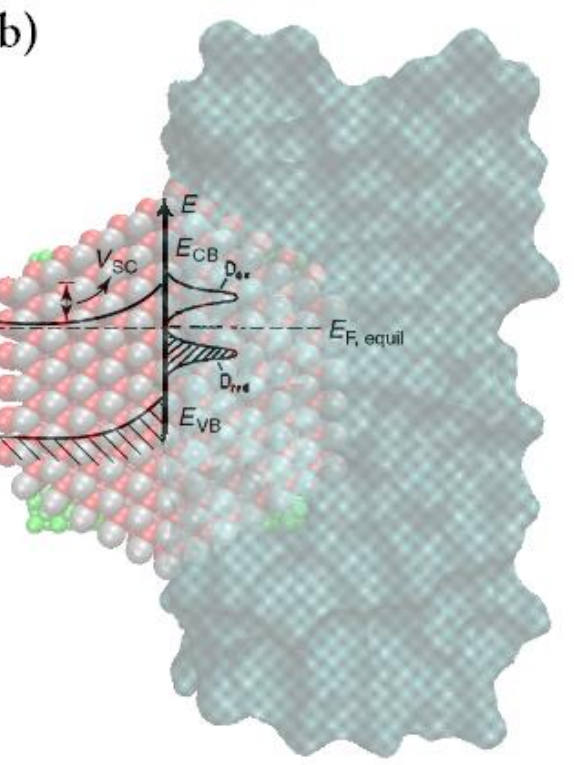

\section{The Electrical Double Layer}

As is the case for metals, the Helmholtz layer of a semiconductor is developed by adsorption of ions or molecules on the material surface, by oriented dipoles, or, especially in the case of oxides, by the formation of surface bonds between the solid surface and the species in solution. For amphoteric $\mathrm{ZnO}$ surfaces, we can write local equilibrium reactions and equilibrium constants [15-17]:

$$
\begin{gathered}
\equiv \mathrm{ZnOH}+H_{(a q)}^{+}=\equiv \mathrm{ZnOH}_{2}^{+} \\
\equiv \mathrm{ZnO}^{-}+H_{(a q)}^{+}=\equiv \mathrm{ZnOH}
\end{gathered}
$$

$\mathrm{K}_{1}$ and $\mathrm{K}_{2}$ are estimated from known thermodynamic data for equilibria of the reactions:

$$
\begin{gathered}
\mathrm{Zn}(\mathrm{OH})_{2(S)}+H_{(a q)}^{+}=\mathrm{ZnOH}_{(a q)}^{+}+\mathrm{H}_{2} \mathrm{O} \\
\mathrm{ZnO}_{2} \mathrm{H}_{(a q)}^{+}+H_{(a q)}^{+}=\mathrm{Zn}(\mathrm{OH})_{2(S)} \\
K_{1}=\frac{\left[\mathrm{ZnOH}_{2}^{+}\right]}{[\mathrm{ZnOH}]\left[\mathrm{H}_{a q}^{+}\right]} \\
K_{2}=\frac{[\mathrm{ZnOH}]}{\left[\mathrm{ZnO}^{-}\right]\left[\mathrm{H}_{a q}^{+}\right]}
\end{gathered}
$$

the equilibrium conditions of reactions 14 and 15 require that:

$$
\begin{gathered}
\bar{\mu}_{\mathrm{ZnOH}}+\bar{\mu}_{\mathrm{H}_{S}^{+}}=\bar{\mu}_{\mathrm{ZnOH}} \\
\bar{\mu}_{\mathrm{ZnO^{- }}}+\bar{\mu}_{\mathrm{H}_{S}^{+}}=\bar{\mu}_{\mathrm{ZnOH}}
\end{gathered}
$$


The concentration of protons at some location near the solid surface in the double layer is related to the bulk concentration by the Boltzmann distribution:

$$
\left[H_{S}^{+}\right]=\left[H_{b}^{+}\right] \exp \left(-\frac{e \psi_{o}}{k T}\right)
$$

Where $\psi_{0}$ is the surface potential of the solid.

Thus, at the surface:

$$
\begin{aligned}
& K_{1}=\frac{\left[\mathrm{ZnOH}_{2}^{+}\right]}{[\mathrm{ZnOH}]\left[\mathrm{H}_{a q}^{+}\right]} \exp \left(-\frac{e \psi_{o}}{k T}\right) \\
& K_{2}=\frac{[\mathrm{ZnOH}]}{\left[\mathrm{ZnO}^{-}\right]\left[\mathrm{H}_{a q}^{+}\right]} \exp \left(-\frac{e \psi_{o}}{k T}\right)
\end{aligned}
$$

In addition to these reactions involving protons or hydroxyl ions, electrolyte counterions could adsorb to neutralize the surface charge (since the diffuse layer charge may be significantly less than the surface charge). To account for specific adsorption of electrolyte ions, Yates et al. [18] proposed the formation of ion pairs or surface complexes at charged surfaces, e.g.:

$$
\begin{gathered}
\equiv \mathrm{ZnO} \mathrm{O}^{-}+\mathrm{Na}_{\mathrm{S}}^{+}=\equiv \mathrm{ZnO}^{-} \mathrm{Na}^{+} \\
\equiv \mathrm{ZnOH}_{2}^{+}+\mathrm{Cl}_{S}^{-}=\equiv \mathrm{ZnOH}_{2}^{+} \mathrm{Cl}^{-}
\end{gathered}
$$

The concentrations of ions in the electrical double layer are expressed in terms of the Boltzmann distribution, e.g.:

$$
\begin{gathered}
{\left[\mathrm{Na}^{+}\right]_{i}=\left[N a^{+}\right] \exp \left(-\frac{e \psi_{\beta}}{k T}\right)} \\
{\left[\mathrm{Cl}^{-}\right]_{i}=\left[C l^{-}\right] \exp \left(-\frac{e \psi_{\beta}}{k T}\right)}
\end{gathered}
$$

where the dissociation constants of reactions (25) and (26) are:

$$
\begin{aligned}
K_{\mathrm{Na}^{+}} & =\frac{\left[\mathrm{ZnO}^{-} \mathrm{Na}^{+}\right]}{\left[\mathrm{ZnO}^{-}\right]\left[\mathrm{Na}^{+}\right]} \exp \left(-\frac{e \psi_{\beta}}{k T}\right) \\
K_{\mathrm{Cl}^{-}} & =\frac{\left[\mathrm{ZnOH}_{2}^{+} \mathrm{Cl}^{-}\right]}{\left[\mathrm{ZnOH}_{2}^{+}\right]\left[\mathrm{Cl}^{-}\right]} \exp \left(-\frac{e \psi_{\beta}}{k T}\right)
\end{aligned}
$$

where $\psi_{\beta}$ is the mean potential at the plane of specifically adsorbed counterions. We can write the reactions as complex ionizations:

$$
\begin{gathered}
\equiv \mathrm{ZnOH}+\mathrm{Na}^{+}=\mathrm{ZnO} \mathrm{O}^{-} \mathrm{Na}^{+}+\mathrm{H}_{S}^{+} \\
\equiv \mathrm{ZnOH}_{2}^{+} \mathrm{Cl}^{-}=\equiv \mathrm{ZnOH}+\mathrm{H}_{S}^{+}+\mathrm{Cl}^{-}
\end{gathered}
$$

where the dissociation constants of reactions (31) and (32) are:

$$
\begin{gathered}
{ }^{*} K_{\mathrm{Na}^{+}}=K_{2} \cdot K_{\mathrm{Na}^{+}} \\
{ }^{*} K_{\mathrm{Cl}^{-}}=\frac{K_{1}}{K_{\mathrm{Cl}^{-}}}
\end{gathered}
$$


and:

$$
\begin{gathered}
{ }^{*} K_{\mathrm{Na}^{+}}=\frac{\left[\mathrm{ZnO}^{-} \mathrm{Na}^{+}\right]\left[\mathrm{H}_{S}^{+}\right]}{[\mathrm{ZnOH}]\left[\mathrm{Na}^{+}\right]} \exp \left(\frac{e}{k T}\left(\psi_{o}-\psi_{\beta}\right)\right) \\
{ }^{*} K_{\mathrm{Cl}^{-}}=\frac{[\mathrm{ZnOH}]\left[\mathrm{H}_{S}^{+}\right]\left[\mathrm{Cl}^{-}\right]}{\left[\mathrm{ZnOH}_{2}^{+} \mathrm{Cl}^{-}\right]} \exp \left(\frac{e}{k T}\left(\psi_{\beta}-\psi_{d}\right)\right)
\end{gathered}
$$

The surface charge, $\sigma_{0}$, is given by:

$$
\sigma_{o}=B\left(\left[\mathrm{ZnOH}_{2}^{+}\right]+\left[\mathrm{ZnOH}_{2}^{+} \mathrm{Cl}^{-}\right]-\left[\mathrm{ZnO}^{-}\right]-\left[\mathrm{ZnO}^{-} \mathrm{Na}^{+}\right]\right)
$$

The charge in the mean plane of specifically adsorbed counterions is:

$$
\begin{gathered}
\sigma_{\beta}=B\left(\left[\mathrm{ZnO}^{-} \mathrm{Na}^{+}\right]-\left[\mathrm{ZnOH}_{2}^{+} \mathrm{Cl}^{-}\right]\right) \\
\mathrm{B}=10^{6} \mathrm{~F} / \mathrm{A}
\end{gathered}
$$

where:

$\mathrm{B}=$ a conversion factor from moles $/$ liter to $\mu \mathrm{C} / \mathrm{cm}^{2}$ of charge.

$\mathrm{A}=$ the surface area of $\mathrm{ZnO}$ immersed in the solution $\left(\mathrm{cm}^{3} /\right.$ liter $)$

$\mathrm{F}=$ the Faraday constant

[Concentration $]=$ moles $/$ liter

and the charge in the diffusion layer is:

$$
\sigma_{d}=-11.74 C^{0.5} \sinh \left(\frac{z e \psi_{d}}{2 k T}\right)
$$

where:

$\mathrm{C}=$ the bulk concentration

$\mathrm{Z}=$ the charge of the supporting electrolyte counter ion in the diffusion layer.

$\psi_{d}=$ the mean potential at the start of the diffusion layer.

Electroneutrality requires that:

$$
\sigma_{o}+\sigma_{\beta}+\sigma_{d}=0
$$

Where $\sigma_{0}, \sigma_{d}$ and $\sigma_{0}$ in $\mu \mathrm{C} / \mathrm{cm}^{2}$.

Ionized surface sites are confined to a mean surface plane, and specifically adsorbed counterions are confined to a second mean potential plane at a distance $\beta$.

Constant capacitances are assumed in the regions between the planes, yielding charge potential relationships [19-21]:

$$
\begin{gathered}
C_{1}=\frac{\sigma_{o}}{\psi_{o}-\psi_{\beta}}=C_{H} \\
C_{2}=-\frac{\sigma_{d}}{\psi_{\beta}-\psi_{d}}=C_{G}
\end{gathered}
$$

where $\mathrm{C}_{\mathrm{H}}$ and $\mathrm{C}_{\mathrm{G}}$ are, respectively, the Helmholtz and Gouy integral capacitances of the inner regions.

The surface species are distributed among the total number of sites available (surface mass balance), $\mathrm{N}_{\mathrm{s}}\left(\right.$ in $\left.\mu \mathrm{C} / \mathrm{cm}^{2}\right)$, which is given by:

$$
N_{S}=B\left(\left[\mathrm{ZnOH}_{2}^{+}\right]+\left[\mathrm{ZnOH}_{2}^{+} \mathrm{Cl}^{-}\right]+[\mathrm{ZnOH}]+\left[\mathrm{ZnO}^{-}\right]+\left[\mathrm{ZnO}^{-} \mathrm{Na}^{+}\right]\right)
$$


If more than one surface layer participates in this exchange process, the effect of the slow process becomes proportionately larger, but since the ions must penetrate more deeply into the solid, the rate of the exchange reaction will decrease with time. Furthermore, the exchange between surface hydroxyls and anions in solution is accompanied by consumption or release of $\mathrm{OH}^{-}$ions, which alters the $\mathrm{pH}$ of the solution in such a way that the driving force for the exchange reaction is diminished. With time, therefore, the observed $\mathrm{pH}$ drift should decrease and cease when a stationary state has been reached.

\section{4. n-Type Semiconductor-Electrolyte Interface: Physical}

The distribution of electric charge at the interface between an n-type semiconductor electrode and an electrolyte solution can be obtained by measuring the interfacial capacitance. There are three regions which are distinguished in the model [22]:

1. The space charge region in the semiconductor, bounded on one side by the surface of the semiconductor and decaying into the electrode bulk. The length of the space charge region depends on the doping density. There is a characteristic region inside the semiconductor within which the charge would have been removed by the equilibration process. Beyond this boundary, the ionized donors (for an n-type semiconductor), have their compensating charge (electrons), and the semiconductor as a whole is electrically neutral. This layer is the space charge region, also known as the depletion layer, so termed because the layer is depleted of the majority carrier.

2. The Helmholtz region. This region adjacent to the semiconductor surface is measured from the plane through the center of the surface atoms of the semiconductor to the Helmholtz plane (the plane through the center of the ions of the electrolyte at their point of closest approach to the semiconductor surface) and is typically $0.3-0.6 \mathrm{~nm}$ in thickness.

3. The space charge region in the electrolyte, bounded on one side by the outer Helmholtz plane and decaying into the bulk of the electrolyte. This region is also called the Gouy diffuse layer.

\section{5. n-Type Semiconductor-Electrolyte Interfaces (without Surface States)}

For this case, the total excess charge per unit area in the semiconductor space charge region is equal and opposite to the excess charge in the electrolyte (assuming the effect of the diffuse double layer in the electrolyte can be eliminated by using electrolytes of sufficiently high concentration, $\sim 1 \mathrm{M}$ ).

The electric charge needed for Fermi level equilibrium in the semiconductor phase originates from the donor impurities (rather than from bonding electrons in the semiconductor lattice). Thus, the depletion layer that arises as a consequence within the semiconductor contains positive charges from these ionized donors. The Fermi level in the semiconductor, $\mathrm{E}_{\mathrm{F}, \mathrm{n}}$, moves down. This process stops when the Fermi level is the same on either side of the interface. The rather substantial difference in the density of states on either side dictates that $\mathrm{E}_{\mathrm{F}, \mathrm{n}}$ moves further than the corresponding level, $\mathrm{E}_{\mathrm{F}, \mathrm{redox}}$, in the electrolyte [23].

The band-bending phenomenon is by no means unique to the semiconductor-electrolyte interface. Analogous electrostatic adjustments occur whenever two dissimilar phases are in contact. An important point of distinction from the corresponding situation involving a metal is that the charge, and thus the associated potential drop, is concentrated at the surface, penetrating at most a few angstroms 
into the interior. Stated differently, the high electrical conductivity of a metal cannot support an internal electric field. Thus, when a metal electrode comes into contact with an electrolyte, almost all of the potential drop at the interface occurs within the Helmholtz region in the electrolyte phase. On the other hand, the interfacial potential drop across a semiconductor-electrolyte junction is partitioned into $\mathrm{V}_{\mathrm{sc}}$ and $\mathrm{V}_{\mathrm{H}}$, leading to a simple equivalent circuit model comprising two capacitors, $\mathrm{C}_{\mathrm{sc}}$ and $\mathrm{C}_{\mathrm{H}}$, in series (see Figure 3) [24,25].

Figure 3. Potential dependence of the capacitance components of the n-type semiconductor-electrolyte interface.

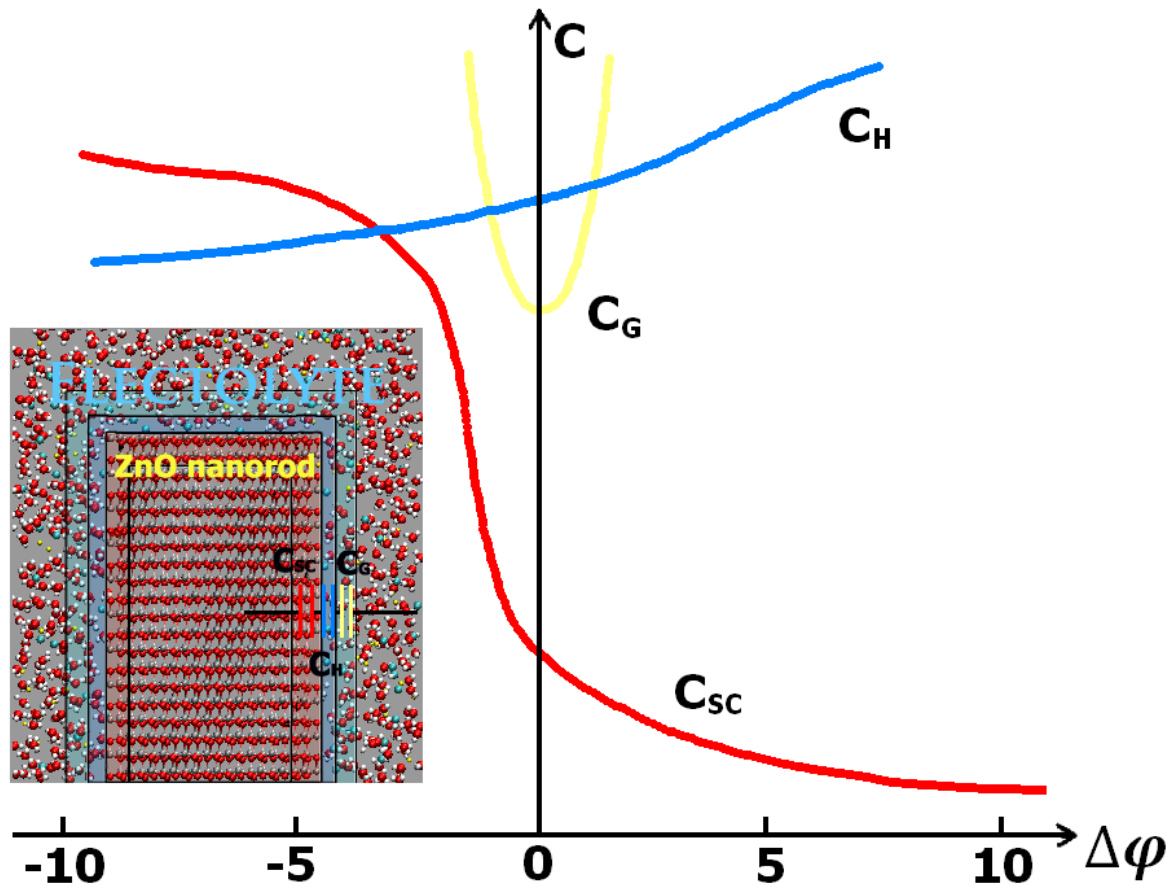

\subsection{Total Potential Difference Across the Interface}

The relative positions of the solution energy levels with respect to the semiconductor band edge positions at the interface can be represented by the total potential difference [26]:

$$
V=V_{S C}+V_{H}+V_{G}
$$

where $\mathrm{V}$ is the electrode potential, as measured between an ohmic contact on the backside of the semiconductor electrode and a reference electrode. The potential difference, $\mathrm{V}_{\mathrm{sc}}$, appears as a bending of the energy bands, as indicated in Figure 2, and the total capacitance, C, in series (see Figure 3) is given by:

$$
\frac{1}{C}=\frac{1}{C_{s c}}+\frac{1}{C_{H}}+\frac{1}{C_{G}}
$$

The problematic factors in placing the semiconductor and solution energy levels on a common basis involve $\mathrm{V}_{\mathrm{H}}$ and $\mathrm{V}_{\mathrm{G}}$. In other words, theoretical predictions of the magnitude of $\mathrm{V}_{\mathrm{sc}}$ (and how it changes as the redox couple is varied) are hampered by a lack of knowledge of the magnitude of $\mathrm{V}_{\mathrm{H}}$ and $\mathrm{V}_{\mathrm{G}}$. 
A degree of simplification is afforded by employing relatively concentrated electrolytes, such that $\mathrm{V}_{\mathrm{G}}$ can be ignored [27] (see Figure 4):

$$
\begin{gathered}
V=V_{s c}+V_{H} \\
\frac{1}{C}=\frac{1}{C_{s c}}+\frac{1}{C_{H}}
\end{gathered}
$$

As with metals, the Helmholtz layer is developed by adsorption of ions or molecules on the semiconductor surface, by oriented dipoles, or, especially in the case of oxides, by the formation of surface bonds between the solid surface and species in solution. Information on band edge placement can be sought through differential capacitance measurements on the semiconductor-redox electrolyte interface [28]. From the capacitor in series model, we can see that the semiconductor space charge layer is usually the determining factor in the total capacitance of the interface. The capacitance of the Helmholtz layer depends only very little on potential. On the other hand, the space charge semiconductor capacitance depends strongly on the potential.

Figure 4. A simplified equivalent circuit for the semiconductor-electrolyte interface at equilibrium where the Gouy layer is neglected.

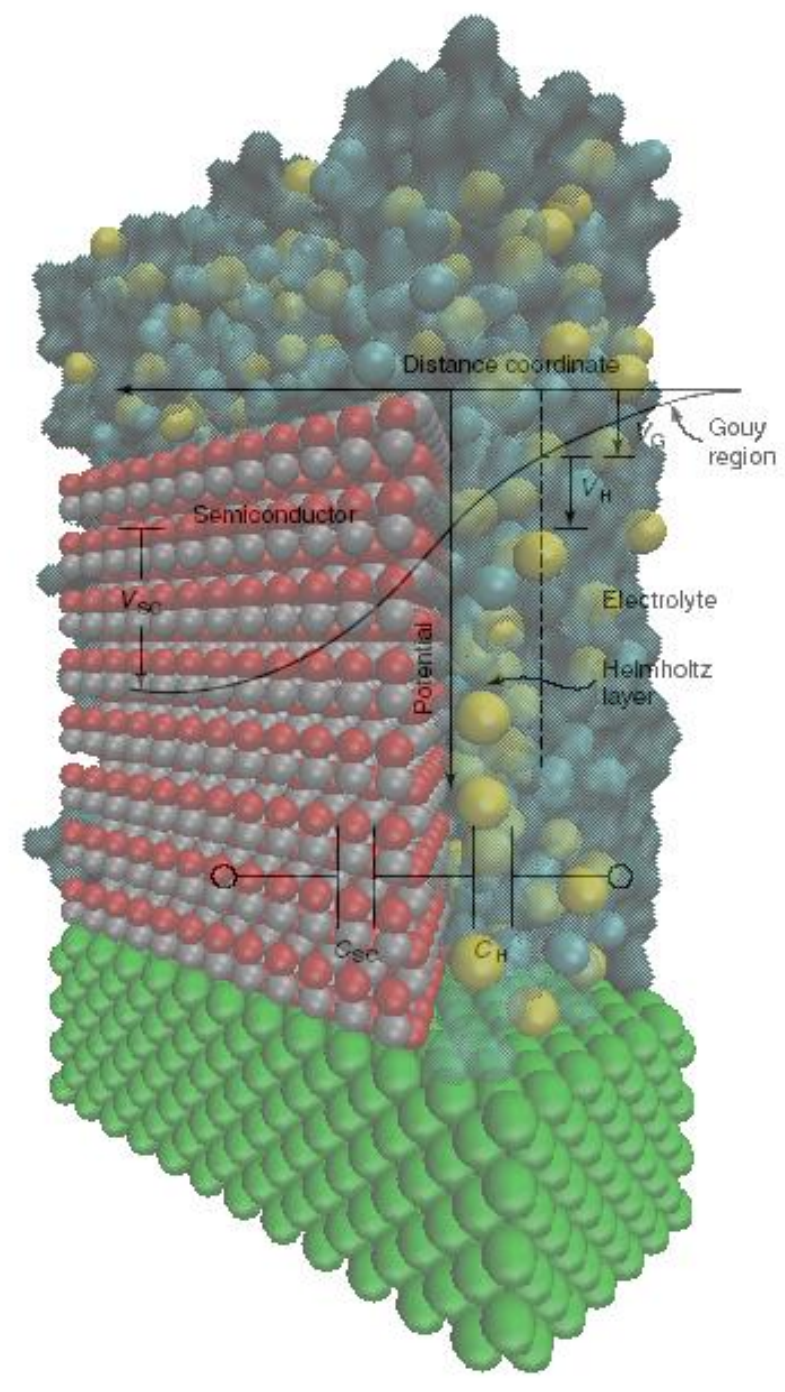


The potential distribution in the space charge layer of a semiconductor can be found by solving the Poisson Equation for a given charge distribution [29,30]. For a semiconductor-electrolyte interface where the density of an electron donor, $\mathrm{N}_{\mathrm{D}}$, is constant throughout the semiconductor, the potential, $\mathrm{V}(\mathrm{x})$, at a distance, $\mathrm{x}$, from the surface is given as follows [29-31]:

$$
V(x)=\frac{q N_{D}}{\varepsilon_{o} \varepsilon_{S}}\left(W x-\frac{1}{2} x^{2}\right)+V(0) \quad \text { where }(0 \leq x \leq W)
$$

where $\mathrm{q}$ is the elementary charge, $\varepsilon_{\mathrm{o}}$ the permittivity of vacuum, $\varepsilon_{\mathrm{s}}$ the dielectric constant of the semiconductor, $\mathrm{V}(0)$ the potential at the surface $(\mathrm{x}=0)$ and the width of the space charge layer $\mathrm{W}$. The values of $\mathrm{V}(0)$ and $\mathrm{W}$ are given by:

$$
\begin{gathered}
V(0)=\frac{q N_{D} W}{\varepsilon_{0} \varepsilon_{S}} \delta \\
W=\left[\frac{2 \varepsilon_{0} \varepsilon_{S}}{q N_{D}}\left(V-V_{f b}-\frac{k T}{q}\right)\right]^{\frac{1}{2}}
\end{gathered}
$$

where $\delta$ is the thickness of the (outer) Helmholtz layer, $\mathrm{V}$ is the electrode potential, and $\mathrm{V}_{\mathrm{fb}}$ is the flat band potential. Further reflection shows how the magnitude of $\mathrm{W}$ should depend on the semiconductor parameter $\mathrm{N}_{\mathrm{D}}$, i.e., the thickness of the space charge layer decreases with increasing doping. For a typical carrier density of $n_{0}=10^{17} \mathrm{~cm}^{-3}$, and a band bending of $\mathrm{V}_{\mathrm{sc}}=0.5 \mathrm{~V}$, one obtains $\mathrm{W}=10^{-5} \mathrm{~cm}$. Nominal dimensions of $\mathrm{W}$ are in the $10-1,000 \mathrm{~nm}$ range. This may be compared with the corresponding Helmholtz layer width, typically $0.4-0.6 \mathrm{~nm}$.

\subsection{The Differential Capacitance of the Space Charge Layer}

The space charge, $Q_{s}$, per unit area is given by [32]:

$$
Q_{s}=q N_{D} W=\left[2 q \varepsilon_{0} \varepsilon_{s} N_{D}\left(V-V_{f b}-\frac{k T}{q}\right)\right]^{\frac{1}{2}}
$$

Thus, the differential capacitance of the space charge layer, $\mathrm{C}_{\mathrm{sc}}$, per unit area is given as follows:

$$
C_{s c}=\frac{\partial Q_{s}}{\partial U}=\left[\frac{2}{q \varepsilon_{0} \varepsilon_{S} N_{D}} \cdot\left(V-V_{f b}-\frac{k T}{q}\right)\right]^{-\frac{1}{2}}
$$

This Equation can be rewritten as follows:

$$
\frac{1}{C_{s c}^{2}}=\frac{2}{q \varepsilon_{o} \varepsilon_{S} N_{D}}\left(V-V_{f b}-\frac{k T}{q}\right)
$$

Equation (54) can be applied to non-degenerate semiconductor systems.

In the above discussion, the energy bands are pinned at the surface, and any variation of the electrode potential leads to a change in the band bending [33-35] (see Figure 2b). Investigations of many semiconductor electrodes have shown that the positions of the energy bands are independent of the doping. Therefore, the energy bands of n-type electrodes have the same position at the surface, as shown in Figure 1. As previously mentioned, in aqueous solutions, the potential across the Helmholtz double layer is entirely determined by the interaction of the semiconductor with the solvent. If the 
energy band edges are pinned, they do not shift upon changing the redox system. Only a change in band bending occurs to maintain equal Fermi levels on both sides of the interface. However, there are many cases where the energy bands are not pinned, but the Fermi level of the semiconductor is pinned [36,37].

The energy positions at the surface for several semiconductors in contact with aqueous solutions are given in Figure 5. In many cases, the flat-band potential $\mathrm{V}_{\mathrm{fb}}$, and consequently the position of the energy bands, varies with the $\mathrm{pH}$ of the solution because of protonation and deprotonation of surface hydroxyl groups. This effect is especially pronounced with oxide semiconductors, germanium and some III-V compounds.

Figure 5. Position of energy bands of various semiconductors with respect to the electrochemical scale (adopted from Ref. [27]).

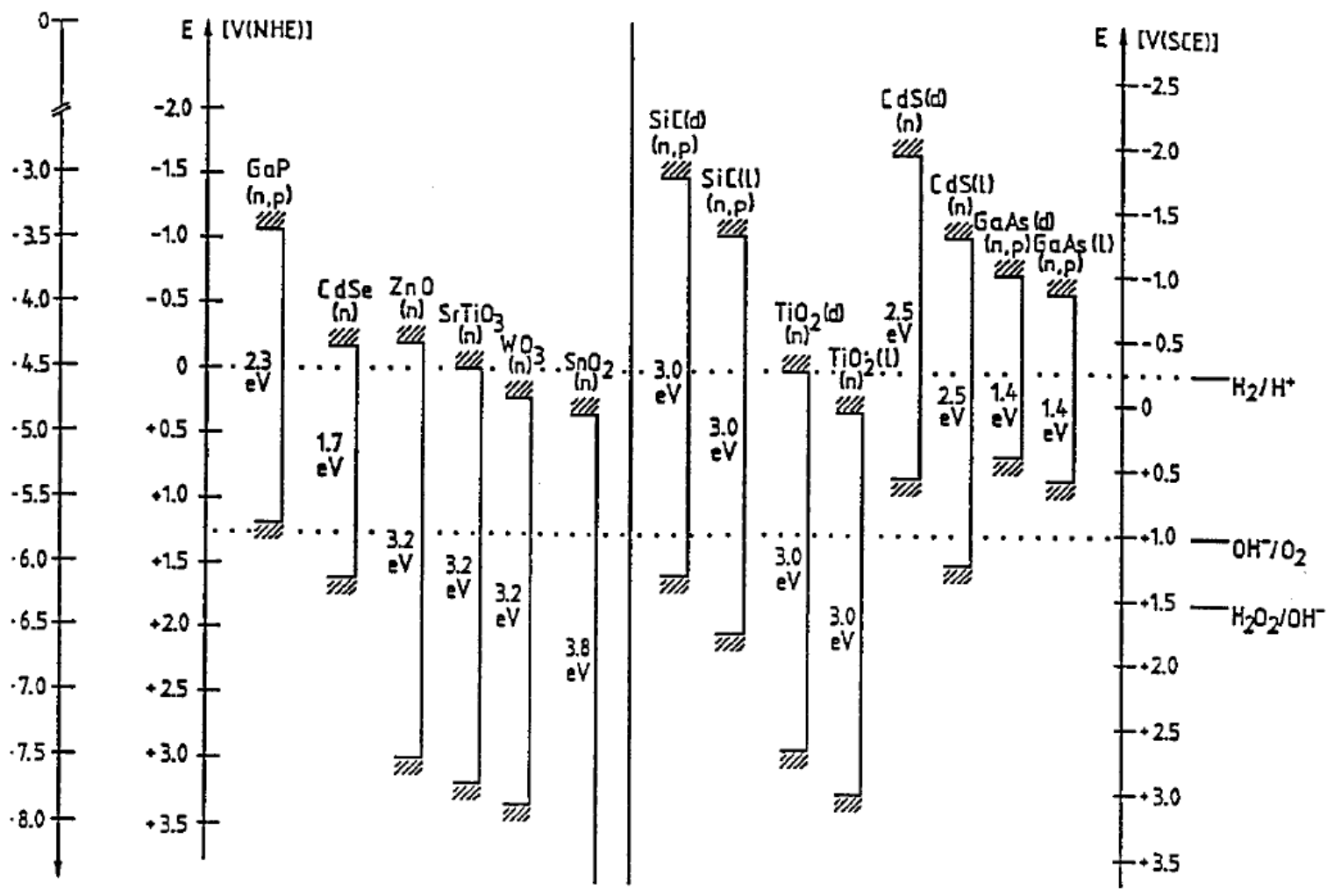

\subsection{Measurement of Differential Capacitance}

The capacitance of the semiconductor-electrolyte interface can be measured by use of a semiconductor electrode, in which the front side of the semiconductor is in contact with the electrolyte and the rear side is electrically connected to a metallic wire via an ohmic contact. The differential capacitance is measured by superimposing an AC voltage, with a small amplitude of about $10 \mathrm{mV}$ and a frequency of a few $\mathrm{Hz}$ to $1 \mathrm{MHz}$, on the electrode potential [38]. 


\subsubsection{Applied potential}

For metallic electrodes, changing the applied potential shifts the Fermi level. The band edges in the interior of a semiconductor (i.e., away from the depletion region) vary with the applied potential in the same way as does the Fermi level in a metal. However, the energies of the band edges at the interface are not affected by changes in the applied potential. Therefore, the change in the energies of the band edges on going from the interior of the semiconductor to the interface, and hence the magnitude and direction of the band bending, varies with the applied potential. There are three different situations to be considered $[39,40]$ :

1. At a certain potential, the Fermi energy lies at the same energy as the solution redox potential (see Figure 6b). There is no net transfer of charge, and there is no band bending. This potential is therefore referred to as the flatband potential $\left(\mathrm{E}_{\mathrm{fb}}\right)$.

2. For an n-type semiconductor, depletion regions arise at potentials positive of the flatband potential (see Figure 6a).

3. For n-type semiconductors at potentials negative of the flatband potential, there is now an excess of the majority charge carrier (electrons) in this space charge region, which is referred to as an accumulation region (see Figure 6c).

The charge transfer abilities of a semiconductor electrode depend on whether there is an accumulation layer or a depletion layer. If there is an accumulation layer, the behavior of a semiconductor is similar to that of a metallic electrode, since there is an excess of the majority charge carrier available for charge transfer. In contrast, if there is a depletion layer, then there are few charge carriers available for charge transfer, and electron transfer reactions occur slowly, if at all.

Figure 6. Effect of varying the applied potential $E$ on the band edges in the interior of an n-type semiconductor where (a) $E>E_{f b}$, (b) $E=E_{f b}$, and (c) $E<E_{f b}$.

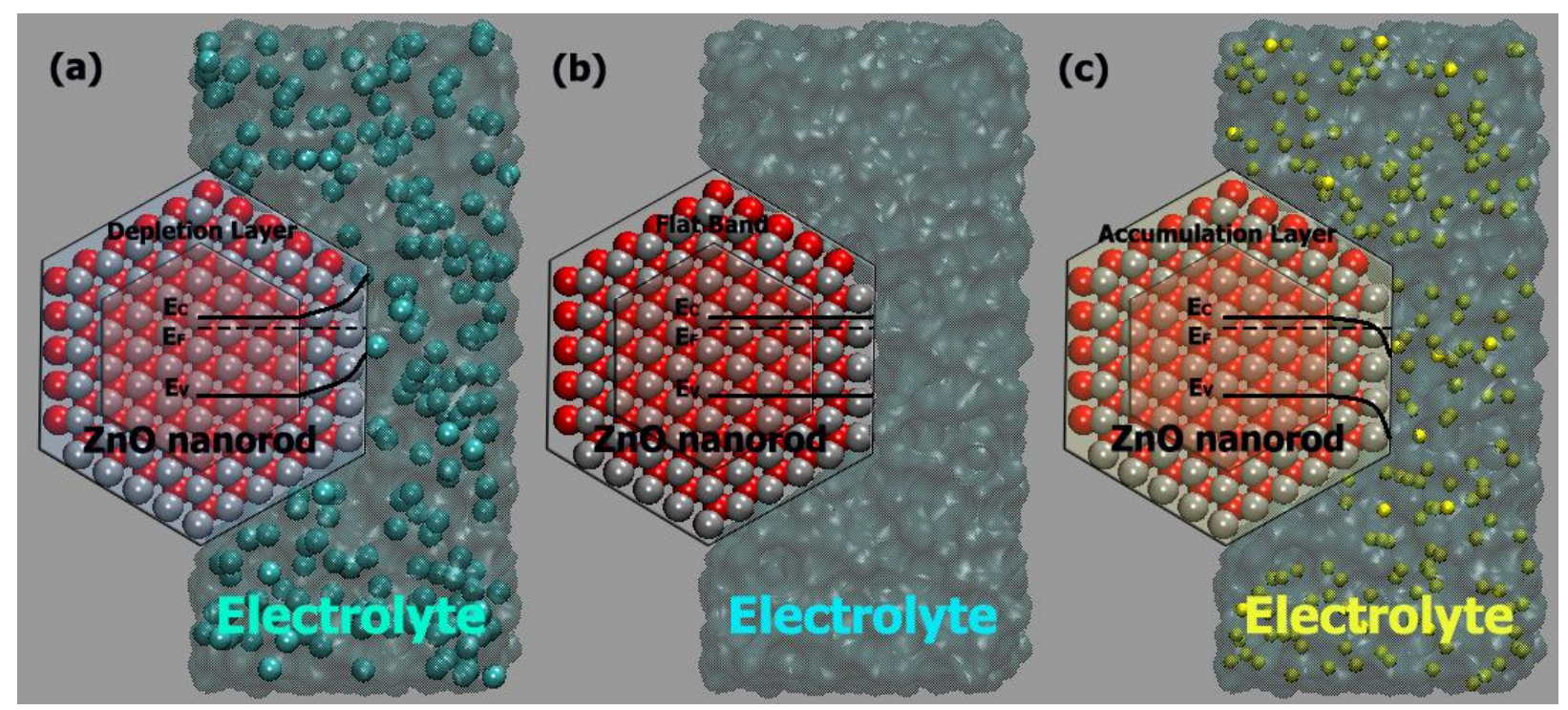




\subsubsection{Mott-schottky plots and flat band potentials}

Using Equation (54), we can create a plot of $1 / \mathrm{C}_{\mathrm{sc}}{ }^{2}$ measured against V. This plot is called the Mott-Schottky plot and gives a straight line with a slope of $\left(2 / \mathrm{q} \varepsilon_{0} \varepsilon_{\mathrm{S}} \mathrm{N}_{\mathrm{D}}\right)$. The extrapolation of the straight line to $1 / \mathrm{C}_{\mathrm{sc}}{ }^{2}=0$ gives $\left(\mathrm{V}_{\mathrm{fb}}+\mathrm{kT} / \mathrm{q}\right)$. Therefore, the plot can be used to determine the flat band potential, $\mathrm{V}_{\mathrm{fb}}$. The donor density, $\mathrm{N}_{\mathrm{D}}$, can also be determined from the slopes of these plots. It should be noted that the slope of the straight line depends not only on $\mathrm{N}_{\mathrm{D}}$ and $\varepsilon_{\mathrm{s}}$ but also on the true surface area (or surface roughness) of the semiconductor electrode [41].

The flat-band potential, $\mathrm{V}_{\mathrm{fb}}$ (the potential at which the bands of the semiconductor become flat, i.e., the potential at which charge in the semiconductor, $\mathrm{Q}_{\mathrm{sc}}$, is zero), is one of the most important quantities for semiconductor electrodes because it determines the band edge positions at the semiconductor-electrolyte interface. These positions, in turn, determine the energies of conduction-band electrons and valence-band holes reacting with the electrolyte solution. It is known that, for most semiconductors such as $\mathrm{n}-\mathrm{ZnO}$ in aqueous electrolytes, $\mathrm{V}_{\mathrm{fb}}$ is solely determined by the solution $\mathrm{pH}$ and shifts in proportion to $\mathrm{pH}$ with a ratio of $-0.059 \mathrm{~V} / \mathrm{pH}[29,30]$ (see Figure 7). This phenomenon is explained by the adsorption equilibrium for $\mathrm{H}^{+}$or $\mathrm{OH}^{-}$at the semiconductor-electrolyte interface.

Figure 7. Mott-Schottky plots for n-type $\mathrm{ZnO}$ in contact with phthalate buffer solutions at pH 4 (circles) and pH 6 (squares) (adopted from Ref. [41]).

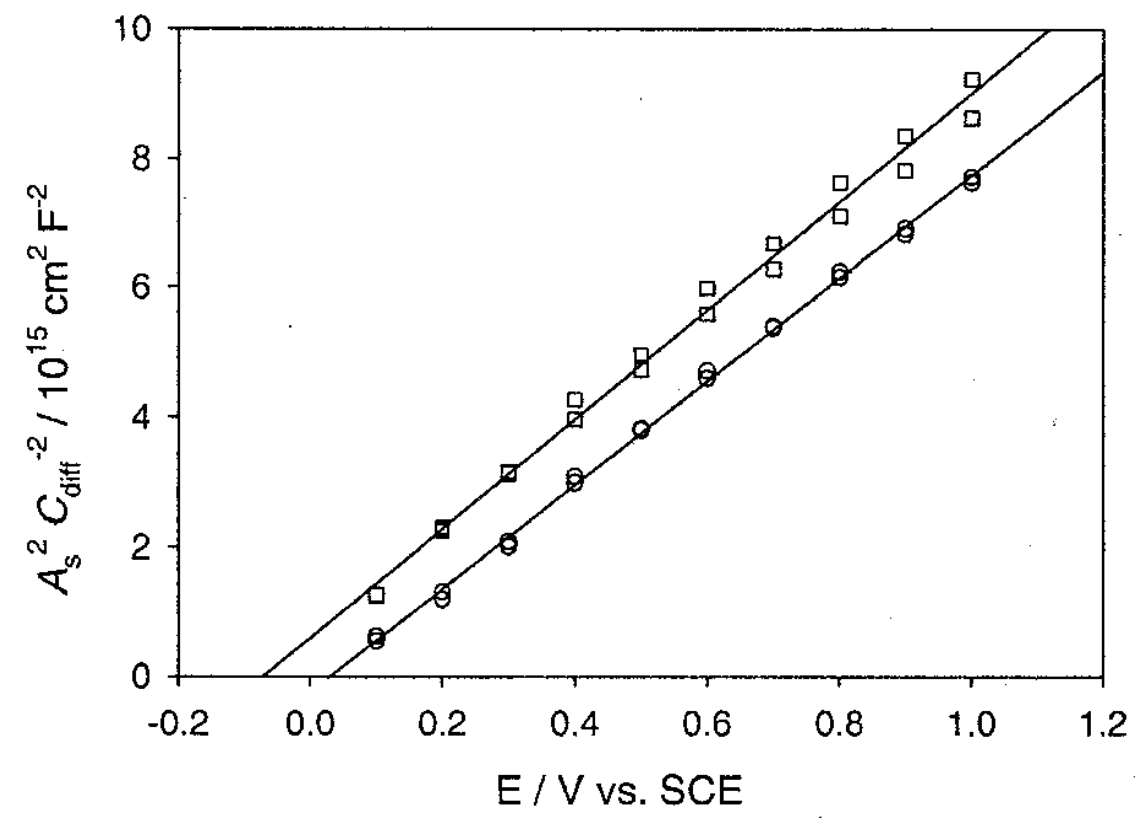

5.3.3. Heavily doped n-type semiconductors $\left(\mathrm{N}_{\mathrm{D}}>10^{20} \mathrm{~cm}^{-3}\right)$

Taking into account the effect of the Helmholtz capacitor and $\mathrm{C}_{\mathrm{sc}}$, the differential capacitance of the space charge layer per unit area is given as follows [42]:

$$
C^{-2}=C_{H}^{-2}\left\lfloor 1+\left(\frac{4 C_{H}^{2}}{\varepsilon_{o} \varepsilon_{s} q N_{D}}\right)\left(V-V_{F B}-\frac{k T}{q}\right)\right\rfloor
$$


As we can see from the above Equation, the relationship between $\mathrm{C}^{-2}$ and $\mathrm{V}$ is linear, and the slope is equal to $\left(2 / \mathrm{q} \varepsilon_{0} \varepsilon_{\mathrm{s}} \mathrm{N}_{\mathrm{D}}\right)$, the same value as in the simple Mott-Schottky relationship [Equation (54)].

However, the intersection with the $\mathrm{V}$ axis gives [42-44]:

$$
V_{o}=V_{F B}+\frac{k T}{q}-\frac{\varepsilon_{o} \varepsilon_{s} q N_{D}}{4 C_{H}^{2}} \text { at } \mathrm{C}^{-2}=0
$$

With respect to the value deduced from Equation (54), this value is shifted by the third term on the right side of the above Equation. The contrast with the corresponding metal-electrolyte interface is striking. The situation becomes similar to the metal-electrolyte interface only when the semiconductor is degenerately doped $\left(\mathrm{N}_{\mathrm{D}}>10^{20} \mathrm{~cm}^{-3}\right.$, which leads to a rather large space charge layer charge, $\mathrm{Q}_{\mathrm{sc}}$ and a thin depletion layer), or when its surface is in accumulation.

Finally, within the Mott-Schottky approximation [Equation (54)], large values of $\varepsilon_{\mathrm{s}}$ or $\mathrm{N}_{\mathrm{D}}$ can lead to large values of the ratio $\mathrm{V}_{\mathrm{H}} / \mathrm{V}_{\mathrm{sc}}$. Figure 8 contains estimates of this ratio for several values of $\mathrm{N}_{\mathrm{D}}$ for a semiconductor with a large $\varepsilon_{\mathrm{s}}$ value, mapped as a function of the total potential drop across the interface [45]. Clearly, $\mathrm{V}_{\mathrm{H}}$ can become a sizable fraction of the total potential drop (approaching the situation for metals) under certain conditions. It has been shown [46] that, in this situation, the Mott-Schottky plots will still be linear, but the intercept on the potential axis is shifted from the $V_{\mathrm{fb}}$ value.

Figure 8. The ratio of the potential drop in the Helmholtz to the total potential change computed as a function of the total potential change. A static dielectric constant of 173 (typical of $\mathrm{TiO}_{2}$ ) and a Helmholtz capacitance of $10 \mu \mathrm{F} / \mathrm{cm}^{2}$ were assumed and the doping density was allowed to vary from $10^{16} \mathrm{~cm}^{-3}$ (curve 1) to $10^{20} \mathrm{~cm}^{-3}$ (curve 13) (adopted from Ref. [45]).

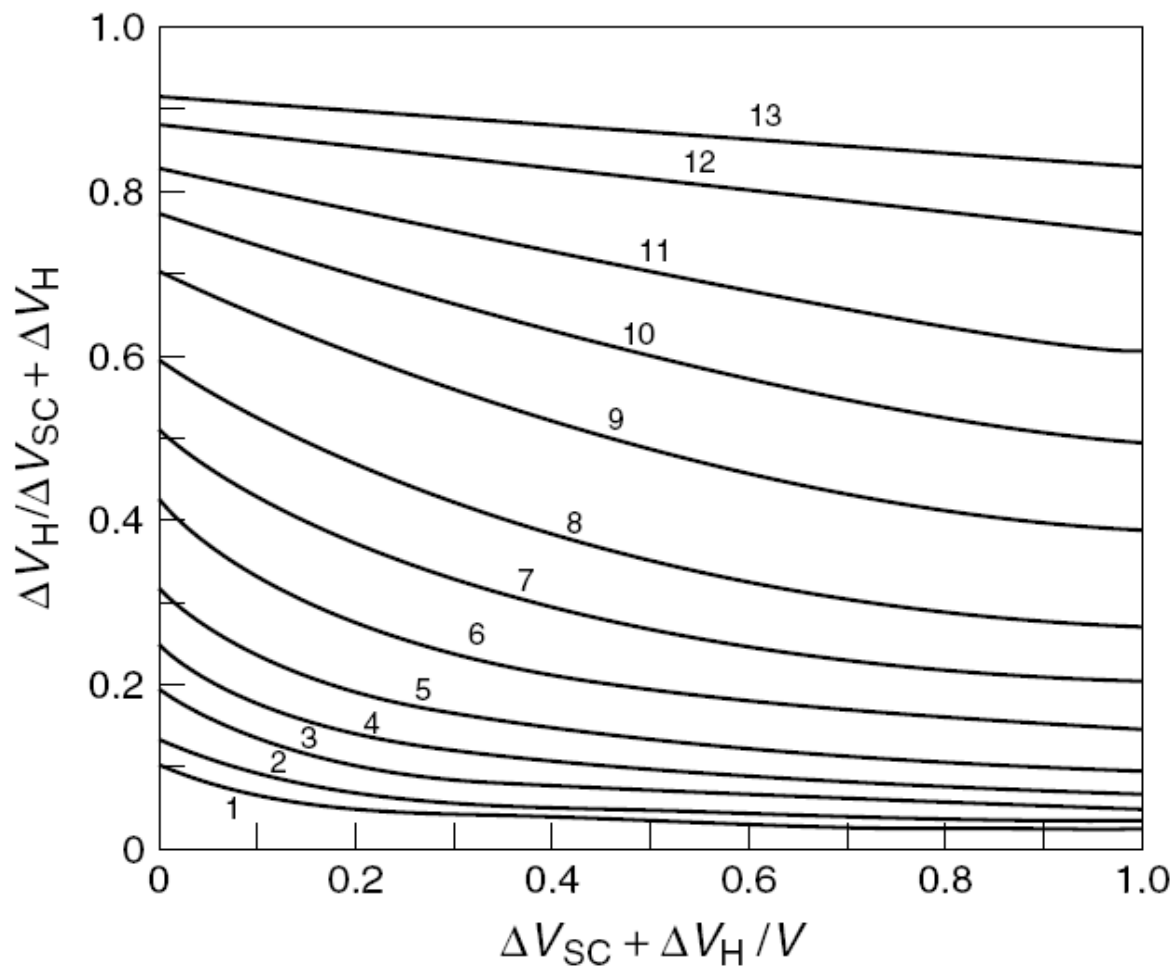




\section{4. n-Type ZnO Nanowire-Electrolyte Interface}

Single crystal $\mathrm{ZnO}$ nanowires have been used to determine the $\mathrm{ZnO}$ carrier density [47-52]. In these studies, Mott-Schottky analysis was used to determine both dopant density and flat-band potential at the $\mathrm{ZnO}$-electrolyte contact. In flat electrodes, the capacitance per unit area of surface is:

$$
\frac{1}{C_{s}^{2}}=\frac{2}{q \varepsilon_{o} \varepsilon_{s} N_{D}}\left(V_{s c}+V_{o}\right)
$$

where $\mathrm{V}_{\mathrm{sc}}$ is the potential difference across the semiconductor space charge region, and $\mathrm{V}_{\mathrm{o}}$ takes into account the contributions of the Helmholtz layer and the flat band potential.

In the nanowire semiconductor structure, a circular depletion layer will grow from the surface towards the center of the wire with increasing bias. The geometry may introduce significant changes with respect to Equation (57). Ivan assumes that each nanowire is described as a cylinder of radius $\mathrm{R}$ with axial symmetry and a donor density $\mathrm{N}_{\mathrm{D}}$. The Poisson Equation in cylindrical coordinates for one dimension is [49]:

$$
\frac{1}{r} \frac{\partial}{\partial r}\left(\frac{\partial V}{\partial r}\right)=-\frac{q N_{D}}{\varepsilon_{o} \varepsilon_{s}}
$$

This Equation can be solved in the depletion approximation for the voltage, V. As shown in Figure (9), the central zone of the cylinder is a neutral region of radius $x$ and electron density $n=N_{D}$. The surface, defined as $\mathrm{x} \leq \mathrm{r} \leq \mathrm{R}$, is a region of positive space charge, $\mathrm{qN}_{\mathrm{D}}$. The reference, $\mathrm{V}=0$, is taken at the semiconductor surface.

Figure 9. Schematic energy diagram in the radial direction of a nanowire indicating the depletion layer at the surface and the quasineutral region of radius $\mathrm{x}$ in the center where $\mathrm{V}$ is the potential, $\mathrm{V}_{\mathrm{sc}}$ is the potential drop across the depletion layer, $\mathrm{E}_{\mathrm{c}}$ is the lower edge of the conduction band, $\mathrm{E}_{\mathrm{F}}$ is the Fermi level (adopted from Ref. [49]).

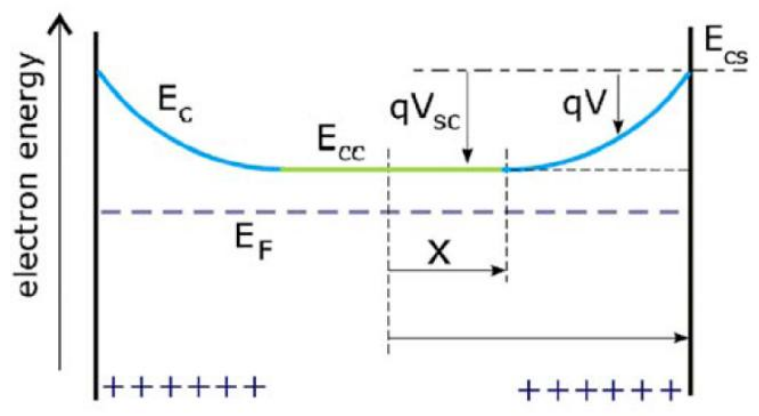

The voltage in the quasineutral region, $\mathrm{V}_{\mathrm{sc}}$, which coincides with the total voltage drop across the barrier, is:

$$
V_{s c}=-\frac{q N_{D}}{2 \varepsilon_{o} \varepsilon_{s}}\left[\frac{1}{2}\left(R^{2}-x^{2}\right)+R^{2} \ln \left(\frac{x}{R}\right)\right]
$$

Figure (10) shows the effect of $\mathrm{N}_{\mathrm{D}}$ on $\mathrm{x}$ as function of $\mathrm{V}_{\mathrm{sc}}$. A high donor density implies an ultra-thin space charge region in $\mathrm{ZnO}$ nanowires. For $\mathrm{N}_{\mathrm{D}}=10^{20} \mathrm{~cm}^{-3}$, this region is limited to less than $3 \mathrm{~nm}$ thickness. The reduction of $\mathrm{N}_{\mathrm{D}}$ by two orders of magnitude causes a considerable portion of 
the nanowire to be depleted. It follows that nanowires with this radius are able to maintain band bending in the vicinity of their surface.

Figure 10. Simulation result of radius of the neutral region vs barrier voltage for different quantities for nanowire of radius $\mathrm{R}=50 \mathrm{~nm}$ and length $\mathrm{L}=1,000 \mathrm{~nm}$, density of nanowires per flat unit area $D_{n w}=3 \times 10^{9} \mathrm{~cm}^{-2}$, flat area $S=1 \mathrm{~cm}^{2}$, and $\varepsilon_{\mathrm{r}}=10$, for two different donor densities $\mathrm{N}_{\mathrm{D}}=10^{18}$ and $\mathrm{N}_{\mathrm{D}}=10^{20} \mathrm{~cm}^{-3}$ (adopted from Ref. [49]).

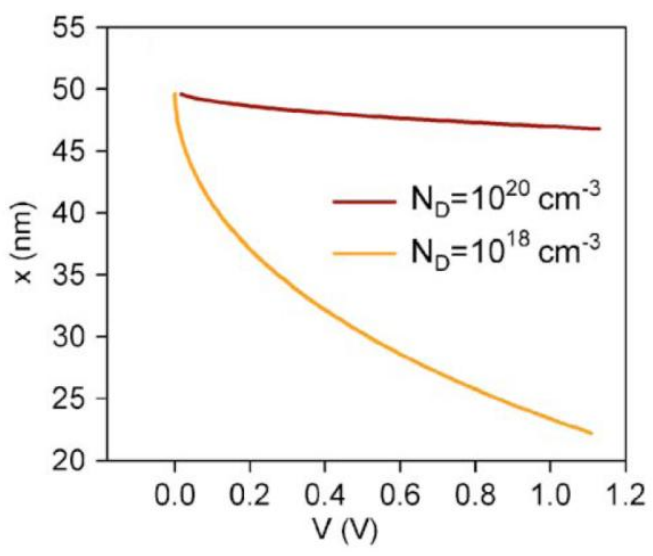

The positive charge in a cylinder of length $\mathrm{L}$ is:

$$
Q=q N_{D} \pi\left(R^{2}-x^{2}\right) L
$$

Computing $\mathrm{dV}_{\mathrm{sc}} / \mathrm{dx}$ and $\mathrm{dQ} / \mathrm{dx}$, we obtain the capacitance as a function of the radius of the neutral region. The capacitance per unit area of the cylinder surface is:

$$
C_{s}=\frac{1}{2 \pi R L} \frac{d Q}{d V_{s c}}=\frac{2 \varepsilon_{o} \varepsilon_{s} x^{2}}{R\left(R^{2}-x^{2}\right)}
$$

The behavior of the capacitance is illustrated in Figure (11).

Figure 11. Simulation result of capacitance vs barrier voltage (adopted from Ref. [49]).

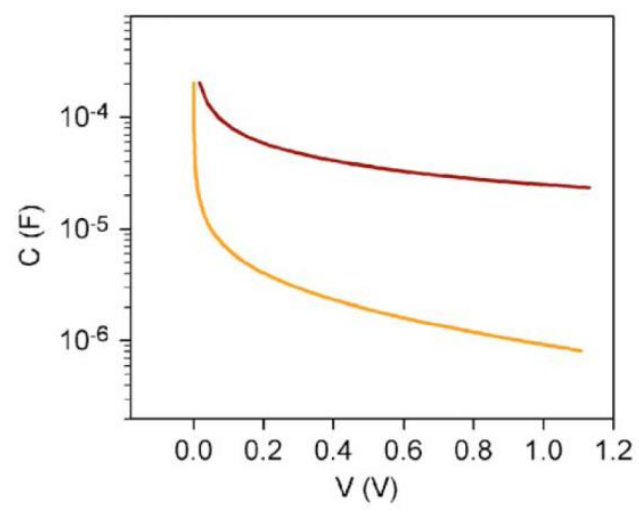

The Mott-Schottky plot for an array of nanowires does not exhibit the linear behavior of Equation (57) observed in flat samples. The deviation from linear behavior decreases as $\mathrm{N}_{D}$ increases. It can be shown that, in the low voltage limit, i.e., $\mathrm{x} \rightarrow \mathrm{R}$ and $\mathrm{V}_{\mathrm{sc}} \rightarrow 0$, the Mott-Schottky plot of a cylindrical sample tends to Equation (57) (see Figure 12). The increase of $N_{D}$ of the nanowire could be due to an 
increase in the number of defects that produce electrically activated donor levels, such as interstitial $\mathrm{Zn}$ atoms $\left(\mathrm{Zn}_{\mathrm{i}}\right)$ and/or $\mathrm{O}$ vacancies $\left(\mathrm{V}_{\mathrm{O}}\right)[53]$ (see Figure 13).

Figure 12. Simulation result of Mott-Schottky plot where the dashed line represents the expected Mott-Schottky using the conventional Equation for a flat interface with $\mathrm{ND}=1,020 \mathrm{~cm}^{-3}$ (adopted from Ref. [49]).

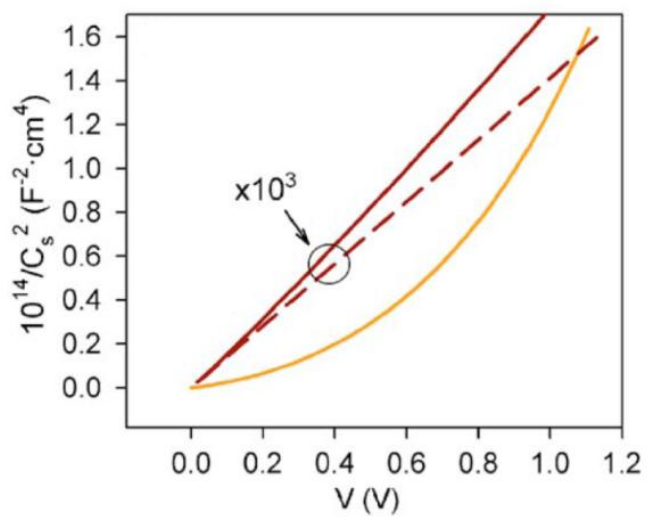

Figure 13. Energy levels of intrinsic defects in $\mathrm{ZnO}$ using Kröger Vink notation: $\mathrm{i}=$ interstitial site, $\mathrm{Zn}=$ zinc, $\mathrm{O}=$ oxygen, and $\mathrm{V}=$ vacancy. The terms indicate the atomic sites, and superscripted terms indicate charges, where a star indicates positive charge, a prime indicates negative charge, and a cross indicates zero charge, with the charges in proportion to the numbers of symbols (values of energy in $\mathrm{eV}$ ).

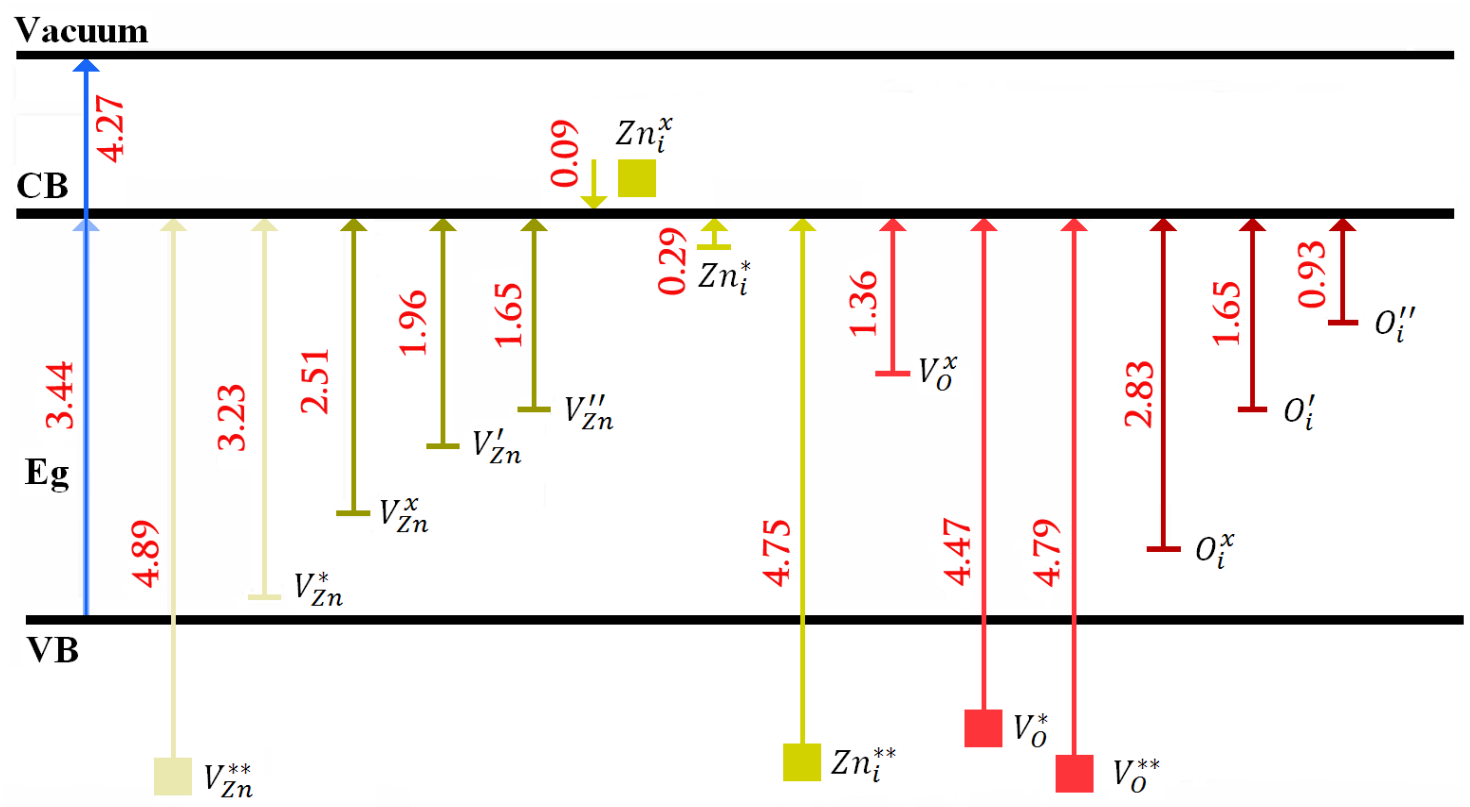

\section{6. n-Type Semiconductor-Electrolyte Interfaces (with Surface States)}

Surface states arise because of the abrupt termination of the crystal lattice at the surface, resulting in a bonding arrangement that is different from that in the bulk (dangling bonds). Consider our 
prototypical semiconductor, $\mathrm{ZnO}$. The tetrahedral bonding characteristic of the bulk gives way to coordinative unsaturation of the bonds for the $\mathrm{Zn}$ and $\mathrm{O}$ surface atoms. This unsaturation is relieved either by surface reconstruction or bonds with extraneous (e.g. solvent) species [54]. The surface bonding results in a localized electronic structure for the surface that is different from that of the bulk. The energies of these localized surface orbitals nominally lie in the forbidden band gap region. The corresponding states are thus able (depending on their energy location) to exchange charge with the conduction band of the semiconductor and/or the redox electrolyte [55] (see Figure 14).

Figure 14. Three situations for a n-type semiconductor-electrolyte interface at equilibrium showing overlap of the redox energy levels with the semiconductor $E_{C}(a)$, with surface states (b), and with the semiconductor $E_{V}(c)$, where the discrete energy level is assumed for the surface states as a first approximation.

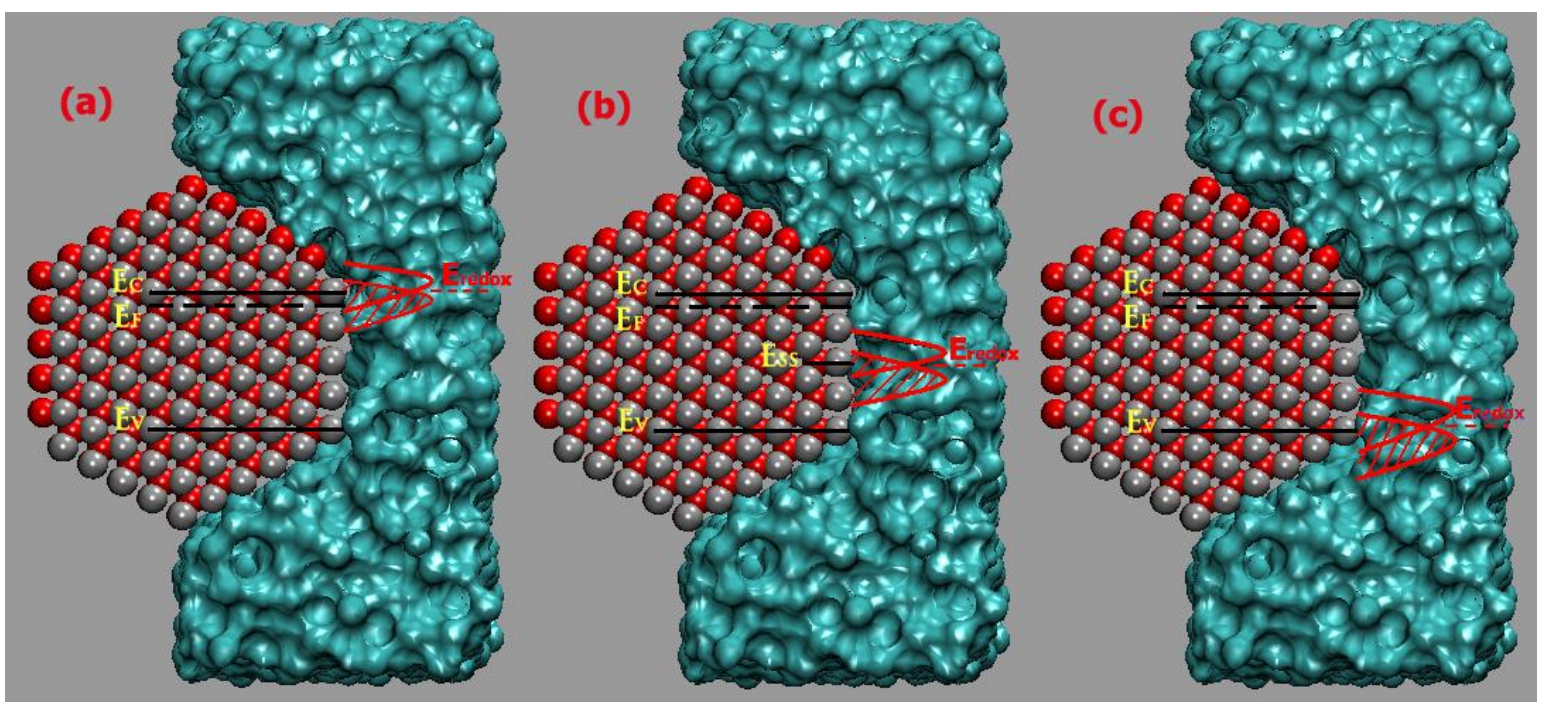

Changes in the solution redox potential have been observed to cause no change in the magnitude of $\mathrm{V}_{\mathrm{sc}}$. This situation is termed Fermi level pinning. In other words, the band edge positions are unpinned in these cases, so that the movement of $E_{\text {redox }}$ is accommodated by $V_{H}$, rather than $V_{\text {sc }}$. It appears [56] that surface state densities as low as $10^{13} \mathrm{~cm}^{-2}(\approx 1 \%$ of a monolayer) suffice to induce complete Fermi level pinning in certain cases. Of course, intermediate situations are also possible. The ideal case manifests a slope of 1 in a plot of $\mathrm{V}_{\mathrm{sc}}$ (or an equivalent parameter) versus $\mathrm{E}_{\text {redox. }}$ On the other hand, complete pinning results in a slope of zero. Intermediate cases of Fermi level pinning exhibit slopes between 0 and 1 [57].

There are two cases for the treatment of a semiconductor/liquid interface in the presence of surface states [58]. First, if there are a large number of states between the valence and conduction band and these states extend throughout the semiconductor, resulting in a continuum of states, the semiconductor is metal-like in its electrode behavior. Such materials are associated with so-called degenerate doping, which provides so many charge carriers that a space-charge region inside the semiconductor is not possible. The behavior of such materials is metal-like. When electronic equilibrium occurs between the electrode and the solution, the potential drop occurs exclusively across the Helmholtz layer at the interface. Variation of the potential between the bulk semiconductor and the solution results in changes 
in the potential drop across the Helmholtz layer and not within the low-resistance semiconductor. Second, the semiconductors may have a significant density of surface states between $\mathrm{E}_{\mathrm{VB}}$ and $\mathrm{E}_{\mathrm{CB}}$ that can exhibit Fermi level pinning when contacting a liquid electrolyte solution. In such a system, (1) many redox couples having different electrochemical potentials give the same output voltage, (2) two couples whose formal potentials are more widely spaced than the separation of $\mathrm{E}_{\mathrm{CB}}$ and $\mathrm{E}_{\mathrm{VB}}$ for a given semiconductor give comparable output voltage, and (3) surface modification aimed at changing the number and location of surface states may be an important way to improve the output characteristics of these electrochemical devices, where Fermi level pinning dominates the properties of the electrode.

\subsection{Fermi Level Pinning}

Fermi level pinning in semiconductor/metal Schottky barriers refers to the phenomenon in which the surface states of a semiconductor give rise to a fixed barrier height, independent of the metal used [59-62]. For some semiconductors, it has been determined that the Schottky barrier height is independent of the metal, even for metals having very large differences in work function. However, when the barrier height is "pinned" to a constant value, it is believed that surface states between $\mathrm{E}_{\mathrm{VB}}$ and $E_{C B}$ must be taken into account. The phenomenon of a metal-insensitive barrier height is referred to as Fermi level pinning and is believed to result from a significant density of surface states at a defined potential. The Fermi level becomes pinned to these states, independent of the overlying metal. Fermi level pinning contributes to the Schottky barrier since the output voltage is limited to a value determined by the surface states of the semiconductor. If Fermi level pinning occurs for certain semiconductor/liquid junctions, we can treat these junctions as Schottky barriers, and attribute the effect to a significant density of surface states that are localized to a certain potential. Thus, the surface states play a role analogous to that in a semiconductor-metal junction. The density and energy distribution of surface states determines their energy level or work function, just as they would for a metal. The result is a semiconductor whose degree of band bending (barrier height) is determined by the layer of surface states. When this is the case, the shift of the flat band potential is due to an unpinning of energy bands. Minority carriers accumulate at the surface, which leads to a change in the potential across the Helmholtz double layer, i.e., $\Delta \mathrm{V}_{\mathrm{fb}}=\mathrm{V}_{\mathrm{H}}$. Band edge unpinning can also occur if carrier inversion develops at the semiconductor electrode surface [63].

In this situation, changes in the Fermi level of the system, due to either changes in the redox system or changes in the applied potential, will shift the energy bands. The total capacitance $C$ (see Figure 15) is given by:

$$
\frac{1}{C}=\frac{1}{C_{s c}+C_{s s}}+\frac{1}{C_{H}}+\frac{1}{C_{G}}
$$

where the total potential drop across the interface, V, caused by excess charge is the sum of the potential drops across the capacitors in series:

$$
V=V_{s c}+V_{H}+V_{G}
$$

The potential drop across $\mathrm{C}_{\mathrm{sc}}$ is the same as the potential drop across $\mathrm{C}_{\mathrm{ss}}$ (as these capacitors are in parallel). 
Qualitatively, Fermi level pinning will be important when the charge in the surface states $\left(\mathrm{Q}_{\mathrm{ss}}\right)$ becomes appreciably larger than that in the space charge region $\left(\mathrm{Q}_{\mathrm{sc}}\right)$. Under these conditions, changes in potential between the bulk semiconductor and the bulk solution will mainly affect the potential drop across the Helmholtz layer, $\mathrm{V}_{\mathrm{H}}$, rather than the drop within the semiconductor $\left(\mathrm{V}_{\mathrm{sc}}\right)$. In this case, even in the absence of an electrolyte solution, band bending within the semiconductor can occur $\left(\mathrm{Q}_{\mathrm{El}}=0\right.$, $\left.\mathrm{Q}_{\mathrm{sc}}=-\mathrm{Q}_{\mathrm{ss}}\right)[64,65]$. For a semiconductor with ionized surface states, the condition of charge neutrality will be:

$$
Q_{s c}=Q_{E l}+Q_{s s}
$$

And, according to the Fermi-Dirac distribution, for singly ionizable surface states, the surface excess charge concentration, $\mathrm{Q}_{\mathrm{ss}}$, is given by $[58,22]$ :

$$
Q_{s s}=\frac{q N_{s s}}{\left[1+g_{s s}^{-1} e^{\left.\frac{-\left[\left(E_{s s}-E_{F}\right)-q V_{s c}\right]}{k T}\right]}\right]}
$$

where $\left(E_{s s}-E_{F}\right)$ is the energy interval between the surface states and the Fermi level when $\mathrm{V}_{\mathrm{sc}}=0$. If the energy bands of the semiconductor are not bent, $\mathrm{g}_{\mathrm{ss}}$ is the degeneracy of the energy level, and $\mathrm{N}_{\mathrm{ss}}$ is the surface concentration of donor states. Given any assumed value of $\mathrm{V}$, if the surface state energy and concentration are known, the individual values of $\mathrm{V}_{\mathrm{sc}}, \mathrm{V}_{\mathrm{H}}$, and $\mathrm{V}_{\mathrm{G}}$ can be calculated. Thus both $\mathrm{Q}_{\mathrm{sc}}$ and $\mathrm{Q}_{\mathrm{ss}}$ are functions of $\mathrm{V}_{\mathrm{sc}}$. For any given value of $\mathrm{V}_{\mathrm{sc}}, \mathrm{Q}_{\mathrm{H}}$ can be obtained using Equation (63).

Figure 15. Approximate equivalent circuits for the n-type $\mathrm{ZnO}$ nanorod-liquid interface in presence of surface states. $\mathrm{C}_{\mathrm{SS}}$ is the surface states capacitance, $\mathrm{C}_{\mathrm{SC}}$ is the semiconductor depletion layer capacitance, $\mathrm{C}_{\mathrm{H}}$ is Helmholtz layer capacitance, and $\mathrm{C}_{\mathrm{G}}$ is Gouy capacitance.

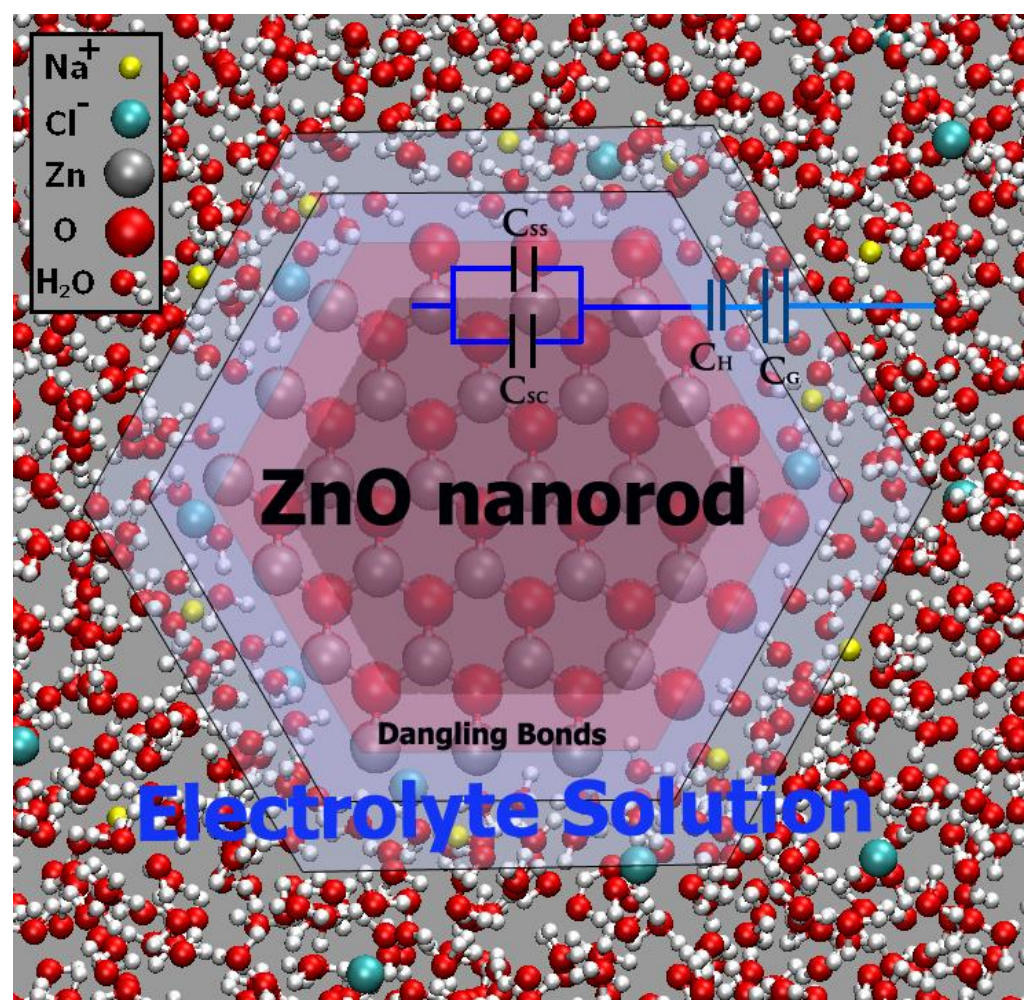


In the presence of surface states, the relation between $\mathrm{Q}_{\mathrm{sc}}$ and $\mathrm{Vsc}$ depends upon the distribution of surface state energies (whether the surface states are uniformly distributed in energy [59] or are localized at a single energy level [66]). For example, if a uniform distribution of acceptor surface states centered on an energy $E_{o}$ is assumed, there is no net surface charge when the states are filled to an energy $E_{0}$. If $Q_{E l}$ is known, $V_{G}$ can be obtained. Similarly, knowledge of $Q_{E l}$ gives the value of $V_{H}$. The essential point which emerges from numerical solutions for semiconductor-electrolyte electrodes with a high concentration of ionized surface states (e.g. $10^{15} \mathrm{~cm}^{-2}, 1 / 10$ ionized) is that $\mathrm{V}_{\mathrm{H}}$ may be large (e.g. $1 \mathrm{~V}$ ). Therefore, for the case of a high concentration of ionized surface states, a semiconductor-electrolyte electrode behaves like a metal-electrolyte electrode. If a potential difference is applied across such a semiconductor-electrolyte electrode and the sum of all changes in potential drops is equal to $\mathrm{V}$, then $\mathrm{V}_{\mathrm{sc}}$ will remain almost the same, while $\mathrm{V}_{\mathrm{H}}$ and $\mathrm{V}_{\mathrm{G}}$ will change. Such behavior is apparent from the fact that a slight shift in $\mathrm{V}_{\mathrm{sc}}$ will cause the ionization or deionization of many surface states. This ionization or deionization will, in turn, change $\mathrm{Q}_{\mathrm{ss}}$ and hence $\mathrm{V}_{\mathrm{H}}$. In this case, the semiconductor-electrolyte electrode behaves like a metal-electrolyte electrode. Note that, within the scope of this treatment, no distinction can be drawn between surface states inherent to the semiconductor surface ("inside" the semiconductor surface) attributable to dangling bonds, surface imperfections, etc. (Tamm [67] or Shockley [68] states), and those formed at the semiconductor surface by adsorption of electron acceptor or donor molecules or by surface modification by intentional attachment of electroactive functionalities. However, ionizable surface groups (groups in which charge is produced by a chemical reaction such as deprotonation) or adsorbed ions can be treated separately, as pointed out by Gerischer [69].

\subsection{Electrochemical Potential of n-Type ZnO Nanorod Electrodes (Potentiometric Measurements)}

Several types of electrodes are used in electrochemical measurements. For this work, we used single-crystal $\mathrm{ZnO}$ nanorods as an electrochemical potential $\mathrm{pH}$ electrode. The Helmholtz layer is developed by adsorption of ions or molecules on the $\mathrm{ZnO}$ nanorod surfaces, by oriented dipoles, or by the formation of surface bonds between the solid surface and species in solution. Water dissociates into hydronium $\mathrm{H}_{3} \mathrm{O}^{+}$and hydroxyl $\mathrm{OH}^{-}$ions, but for simplicity we refer to the hydronium ion as a hydrogen ion $\mathrm{H}^{+}$in chemical reaction Equations. The metal atoms in an amphoteric oxide must be fairly electropositive to give the oxygen sufficient negative charge to strip a proton from a neighboring $\mathrm{H}_{3} \mathrm{O}^{+}$. However, the metal ion must also be electronegative enough to serve as an electron acceptor from a neighboring $\mathrm{OH}^{-}$. For amphoteric $\mathrm{ZnO}$ surfaces, we can write local equilibrium reactions and equilibrium constants:

$$
\begin{array}{ll}
\mathrm{Zn}(\mathrm{OH})_{2(S)}+H_{(a q)}^{+}=\mathrm{ZnOH}_{(a q)}^{+}+\mathrm{H}_{2} \mathrm{O} & \text { for acid } \\
\mathrm{ZnO}_{2} \mathrm{H}_{(a q)}^{+}+H_{(a q)}^{+}=\mathrm{Zn}(\mathrm{OH})_{2(S)} & \text { for base }
\end{array}
$$

where $\mathrm{K}_{1}$ and $\mathrm{K}_{2}$ are the dissociation constants, which can be estimated from known thermodynamic data for equilibria of the reactions:

$$
K_{1}=\frac{\left\lfloor\mathrm{ZnOH}^{+}\right\rfloor}{\left[\mathrm{Zn}(\mathrm{OH})_{2}\right]\left[\mathrm{H}^{+}\right]}
$$




$$
K_{2}=\frac{\left[\mathrm{Zn}(\mathrm{OH})_{2}\right]}{\left[\mathrm{ZnO}_{2} \mathrm{H}^{+}\right]\left[\mathrm{H}^{+}\right]}
$$

If these $\mathrm{ZnO}$ nanorods are degenerately doped $\left(\mathrm{N}_{\mathrm{D}}>10^{20} \mathrm{~cm}^{-3}\right)$, they possess a rather large space charge layer charge, $\mathrm{Q}_{\mathrm{sc}}$ and a thin depletion layer. In this instance, the situation becomes similar to a metal-electrolyte interface. The increase in $N_{D}$ in the nanorods could be due to an increase in the number of defects that produce electrically activated donor levels, such as interstitial $\mathrm{Zn}$ atoms $\left(\mathrm{Zn}_{\mathrm{i}}\right)$ and/or $\mathrm{O}$ vacancies $\left(\mathrm{V}_{\mathrm{O}}\right)$. When electronic equilibrium occurs between the electrode and the solution, the potential drop occurs exclusively across the Helmholtz layer at the interface. The electrochemical potential difference between $\mathrm{ZnO}$ nanorods and the solution results from changes in the potential drop across the Helmholtz layer and not within the low-resistance $\mathrm{ZnO}$ nanorod. We interpret this result as Fermi level pinning by surface states. At $\mathrm{pH}<9$, on the first contact of $\mathrm{ZnO}$ nanorods with the aqueous solution, adsorption of $\mathrm{H}^{+}$on $\equiv \mathrm{ZnOH}$ groups near the surface takes place. At $\mathrm{pH}>9$, on the first contact of $\mathrm{ZnO}$ nanorods with the aqueous solution, $\equiv \mathrm{ZnOH}$ groups combine with $\mathrm{OH}$ ions, forming $\equiv \mathrm{ZnO}^{-}$. In terms of solid state chemistry, $\equiv \mathrm{ZnOH}^{+}$and $\equiv \mathrm{ZnO}^{-}$groups form surface states.

During electrochemical potential $\mathrm{pH}$ measurements, the $\mathrm{ZnO}$ nanorods are positively charged, which provides a suitable environment for adsorption of low isoelectric point groups. Because of this suitability, we will use the chemical reaction in Equation (65) to find the electrochemical potential Equation for our $\mathrm{ZnO}$ nanorod sensor. The electrical potential difference, $\Delta \Phi$, between the electrolyte solution and the $\mathrm{ZnO}$ nanorods can be expressed as:

$$
\Delta \Phi=\Phi_{E l}-\Phi_{M O}=\frac{1}{n F}\left(\mu_{\mathrm{ZnOH}^{+}}+\mu_{\mathrm{H}_{2} \mathrm{O}}-\mu_{\mathrm{Zn}(\mathrm{OH})_{2}}-\mu_{\mathrm{H}^{+}}\right)
$$

where $\Phi_{E l}$ is the electrical potential of the electrolyte solution, $\Phi_{M O}$ is the electrical potential of the inert $\mathrm{ZnO}$ nanorod electrode, $n$ is the number of electrons in the redox reaction, and $\mu_{i}$ is the chemical potential of species $i$.

Equation (69) may thus be rewritten in the form of the Nernst Equation for the simple redox electrode:

$$
\Delta \Phi=E_{\mathrm{Zn}(\mathrm{OH})_{2} \mid \mathrm{ZnOH} H^{+}}=\frac{1}{n F}\left(\mu_{\mathrm{ZnOH}}^{o}-\mu_{\mathrm{Zn}(\mathrm{OH})_{2}}^{o}-\mu_{\mathrm{H}^{+}}^{o}\right)+\frac{R T}{n F} \ln \left(\frac{a_{\mathrm{ZnOH}^{+}}}{a_{\mathrm{Zn}(\mathrm{OH})_{2}} \cdot a_{\mathrm{H}^{+}}}\right)
$$

where $\mu_{i}^{o}$ is the standard chemical potential of species $i$ at unit activity $a_{i}=1$, and $a_{i}$ is the activity of the particular ions. For the redox system employed here, we obtain:

$$
E_{\mathrm{Zn}(\mathrm{OH})_{2} \mid \mathrm{ZnOH}^{+}}^{o}=\frac{1}{n F}\left(\mu_{\mathrm{ZnOH}}^{o}-\mu_{\mathrm{Zn}(\mathrm{OH})_{2}}^{o}-\mu_{\mathrm{H}^{+}}^{o}\right)
$$

where $E^{o}$ is the standard electrode potential of the $\mathrm{ZnO}$ nanorod redox electrode.

$$
E_{\mathrm{Zn}(\mathrm{OH})_{2} \mid \mathrm{ZnOH}^{+}}=E_{\mathrm{Zn}(\mathrm{OH})_{2} \mid \mathrm{ZnOH}}^{o}+\frac{R T}{n F} \ln \left(\frac{a_{\mathrm{ZnOH}^{+}}}{a_{\mathrm{Zn}(\mathrm{OH})_{2}} \cdot a_{\mathrm{H}^{+}}}\right)
$$

At ideal dilution, if the activity, $a_{i}$, is identical to the concentration, $c_{i}$, then $a_{i} \approx c_{i}=[i]$. The electrochemical potential of the $\mathrm{ZnO}$ nanorod electrode will be: 


$$
E_{\mathrm{Zn}(\mathrm{OH})_{2} \mid \mathrm{ZnOH}^{+}}=E_{\mathrm{Zn}(\mathrm{OH})_{2} \mid \mathrm{ZnOH}}^{o}+\frac{R T}{n F} \ln \left(\frac{\left\lfloor\mathrm{ZnOH}^{+}\right\rfloor}{\left[\mathrm{Zn}(\mathrm{OH})_{2}\right] \cdot\left[\mathrm{H}^{+}\right]}\right)
$$

The value of $R T / F$ is approximately equal to $25.684 \mathrm{mV}$. For $\mathrm{n}=1$, the expression above (73) can be simplified to give:

$$
E_{\mathrm{Zn}(\mathrm{OH})_{2} \mid \mathrm{ZnOH}^{+}}=E_{\mathrm{Zn}(\mathrm{OH})_{2} \mid \mathrm{ZnOH}^{+}}^{o}+(0.05915) \log \left(\frac{\left\lfloor\mathrm{ZnOH}^{+}\right\rfloor}{\left[\mathrm{Zn}(\mathrm{OH})_{2}\right]}\right)+(0.05915) \lg \left(\frac{1}{\left[\mathrm{H}^{+}\right]}\right)
$$

The potential of the $\mathrm{ZnO}$ nanorod $\mathrm{pH}$ electrode is:

$$
E_{\mathrm{Zn}(\mathrm{OH})_{2} \mid \mathrm{ZnOH}^{+}}=E_{\mathrm{Zn}(\mathrm{OH})_{2} \mid \mathrm{ZnOH}^{+}}^{o}+(0.05915) \log \left(\frac{\left\lfloor\mathrm{ZnOH}^{+}\right\rfloor}{\left[\mathrm{Zn}(\mathrm{OH})_{2}\right]}\right)+(0.05915) \mathrm{pH}
$$

with $-\log \left(a_{H^{+}}\right)=p H$. The last term on the right hand side of Equations (74) and (75) suggests that it is possible to use these electrodes as Nernstian $\mathrm{pH}$ sensors.

The electrochemical device used here consists of a $\mathrm{Ag}_{(s)}\left|\mathrm{AgCl}_{(s)}\right| \mathrm{Cl}^{-}$electrode as a reference electrode. This reference supplied a constant potential, $E_{\mathrm{Ag} / \mathrm{AgCl} / \mathrm{Cl}}{ }^{-}$, against which we measured the potential of the $\mathrm{ZnO}$ nanorod redox electrode. We fabricated the $\mathrm{ZnO}$ nanorod sensor by growing hexagonal, single-crystal $\mathrm{ZnO}$ nanorods on silver-coated substrates using a low-temperature growth method described previously [70-72] (see Figure 16).

Figure 16. SEM images of the $\mathrm{ZnO}$ nanorods grown on Ag-coated n-Si substrate using low temperature growth (different magnification of the same sample).

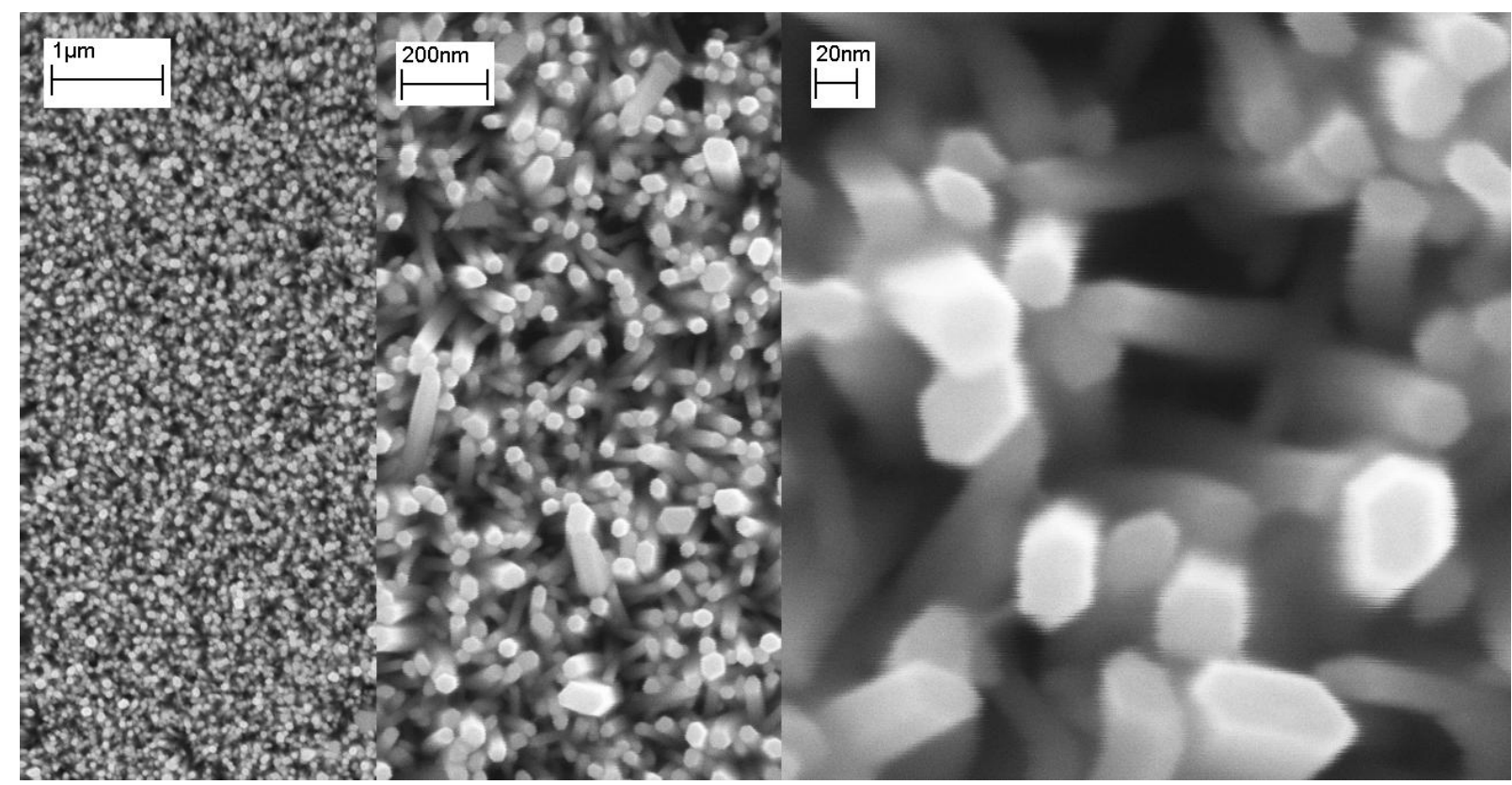

The resultant nanostructure is rod-shaped with a hexagonal cross section and is primarily aligned perpendicular to the substrate, a typical morphology of the wurtzite $\mathrm{ZnO}$ structure. The nanorods are 
uniform in size, with a diameter of 20-60 $\mathrm{nm}$ and a length of $500 \mathrm{~nm}$ [73]. The electrochemical device in this study can be represented as:

$$
\mathrm{Ag}\left|\mathrm{AgCl}_{(s)}\right| \mathrm{Cl}^{-}:_{2} \mathrm{O}\left|\mathrm{ZnOH}^{+}\right| \mathrm{Zn}(\mathrm{OH})_{2}
$$

The device e.m.f. $(E)$ is the potential difference between the supplied potential of the $Z n O$ redox working electrode, $E_{\mathrm{ZnO} / \mathrm{ZnOH}}{ }^{+}$, and the supplied potential of the standard reference electrode, $E_{\mathrm{Ag} / \mathrm{AgCl} / \mathrm{Cl}}^{-}$:

$$
E=E_{\mathrm{Zn}(\mathrm{OH})_{2} \mid \mathrm{ZnOH}}-E_{A g|A g C l| C l^{-}}=E_{\mathrm{Zn}(\mathrm{OH})_{2} \mid \mathrm{ZnOH} H^{+}}^{o}+(0.05915) \log \left(\frac{\left\lfloor\mathrm{ZnOH}^{+}\right\rfloor}{\left[\mathrm{Zn}(\mathrm{OH})_{2}\right]}\right)+(0.05915) \cdot p H-E_{\mathrm{Ag}|\mathrm{AgCl}| \mathrm{Cl}{ }^{-}}
$$

We used a two-electrode configuration and milliliter sample volumes in these electrochemical studies. The $\mathrm{ZnO}$ nanorods functioned as the working electrode, and we used a standard $\mathrm{Ag} / \mathrm{AgCl}$ reference electrode. All electrochemical experiments were conducted using a Metrohm model $827 \mathrm{pH}$ meter at room temperature $\left(22 \pm 2{ }^{\circ} \mathrm{C}\right)$. We measured the electrochemical potential response of the $\mathrm{ZnO}$ nanorods (as a working electrode versus the $\mathrm{Ag} / \mathrm{AgCl}$ reference electrode) to changes between standard buffers at room temperature. The results of this experiment show that this $\mathrm{pH}$ dependence is linear and has a sensitivity of $51.881 \mathrm{mV} / \mathrm{pH}$ at $22{ }^{\circ} \mathrm{C}$ (see Figure 17 [73]).

Figure 17. Calibration curve showing the electrochemical potential difference for $\mathrm{ZnO}$ nanorods as a working electrode with a $\mathrm{Ag} / \mathrm{AgCl}$ reference microelectrode vs $\mathrm{pH}$ changes for buffer solutions (adopted from Ref. [73]).

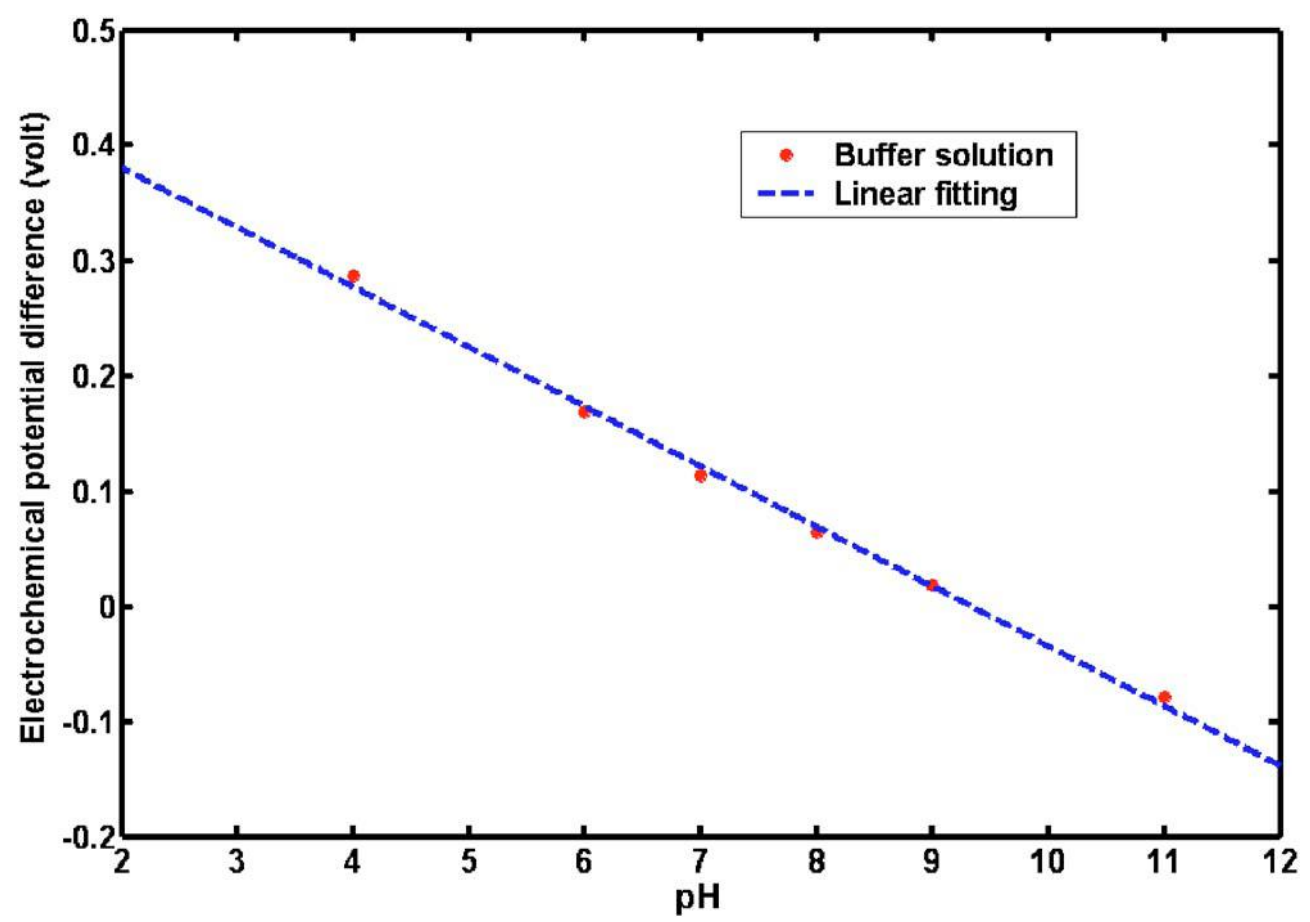




\section{7. n-Type ZnO Sensing Mechanism}

\subsection{Surface Composition and Variation in PZC}

The observed variations in point of zero charge (pzc) between the different zinc oxide precipitates may be related to changes in surface composition. It is known that anionic impurities generally lower the pzc of many oxides [74-76]. Parks explained this observation qualitatively by postulating that the surface group $\mathrm{M}-$ anion $-\mathrm{H}$ is a stronger acid than the surface group $\mathrm{M}-\mathrm{O}-\mathrm{H}$, where $\mathrm{M}$ designates the metallic cation [74]. It would be more satisfactory to compare, for example, the surface states $\mathrm{M}-\mathrm{C} 1{ }^{\cdots} \mathrm{H}$ and $\mathrm{M}-\mathrm{OH}{ }^{\cdots} \mathrm{H}$ and to ascribe the stronger acid-like nature of the former to an increased polarization of the larger anion and the inability of the chloride atom to hydrogen bond water molecules. $\mathrm{ZnO}$ that was prepared in a highly alkaline solution with excess base showed a pzc greater than $\mathrm{pH}$ 9.5, whereas samples formed at a less basic $\mathrm{pH}$ with a large excess of $\mathrm{NO}_{3}{ }^{-}$had a pzc close to $\mathrm{pH}$ 8. The pzc values of other precipitates that should have impurity contents intermediate to these extremes were observed to vary between $\mathrm{pH} 8.5$ and $\mathrm{pH} 9.5$.

Anionic impurities, if present, should be leached out of the surface during a refluxing operation, and the pzc of the leached precipitate should fall at a higher $\mathrm{pH}$ than that of the unleached precipitate. The existence of a solid solution of $\mathrm{Zn}(\mathrm{OH})_{2}$ and $\mathrm{Zn}(\mathrm{OH})_{1.6} \mathrm{X}_{0.4}$ on the surface of zinc oxide has been postulated in order to explain the observed behavior in pzc. This composition model of the surface layer makes it possible to interpret the ion exchange process involving the anionic species $\mathrm{OH}^{-}$and $\mathrm{X}^{-}$. It also helps to explain, qualitatively at least, the observed dependence of the pzc on the method of preparation of various zinc oxides [75].

\subsection{Interface Mechanism}

The diffusing species in the solid might be $\mathrm{H}^{+}$at $\mathrm{pH}<9$ and $\mathrm{OH}^{-}$at $\mathrm{pH}>9 . \mathrm{H}^{+}$ions should have a much higher diffusivity in $\mathrm{ZnO}$ than $\mathrm{OH}^{-}$. This characteristic might not be observed, however, if $\mathrm{OH}$ groups exist in the bulk of the initial $\mathrm{ZnO}$ at point defects. At $\mathrm{pH}>9$, the protons of such groups could diffuse out of the $\mathrm{ZnO}$. The objection that charge would accumulate in the solid by such a process might be answered by assuming simultaneous transfer of counterions $\left(\mathrm{Cl}^{-}\right.$at $\mathrm{pH}<9, \mathrm{Na}^{+}$at $\left.\mathrm{pH}>9\right)$ to the region behind the electrokinetic slipping plane. However, such diffusion would be influenced by the electric potential generated. If the counterions remain outside the solid (or penetrate the solid only at dislocations), whereas $\mathrm{H}^{+}$diffuses into and out of undisturbed regions of $\mathrm{ZnO}$, we could find the surface potential at the boundaries of these undisturbed regions by solving Poisson's relation (for a flat surface see section 5.1, for the cylinder surface see section 5.4). The proton concentration in $\mathrm{ZnO}$ decreases to $1 / \mathrm{e}$ of its surface concentration well within one unit cell, which excludes a diffusion-controlled process. Simultaneous diffusion of equimolar quantities of $\mathrm{H}^{+}$and $\mathrm{Cl}^{-}$into the $\mathrm{ZnO}$ at $\mathrm{pH}<9$, or exchange of $\mathrm{Na}^{+}$against $\mathrm{H}^{+}$at $\mathrm{pH}>9$, would remove this discrepancy. In order to be sterically possible, such a process should be restricted to dislocations. At the first contact of $\mathrm{ZnO}$ with an aqueous solution, adsorption of $\mathrm{H}^{+}$and $\mathrm{OH}^{-}$occurs (indicated as "primary adsorption"). This process is saturated at a relatively low degree of surface coverage. In addition, a reaction of surface $\equiv \mathrm{Zn}-\mathrm{OH}$ groups takes place with $\mathrm{H}^{+}$ions at $\mathrm{pH}<9$ and with $\mathrm{OH}^{-}$ions at $\mathrm{pH}>9$. The rate of 
this reaction is proportional to the concentration of free electrons or holes (vacant states in the valence band) at the surface. The charge, transferred by this process to the solid, does not remain at the surface itself but is distributed by electron transport over the near-surface region of the solid. This process forms a depletion layer or counteracts an accumulation layer at $\mathrm{pH}<9$ and forms or enhances an accumulation layer at $\mathrm{pH}>9$ (see Figure 18) [77].

Figure 18. Schematic representation of the distribution of charges due to the slow reaction:

(a) at $\mathrm{pH}<8.9$, (b) at $\mathrm{pH}>8.9$.
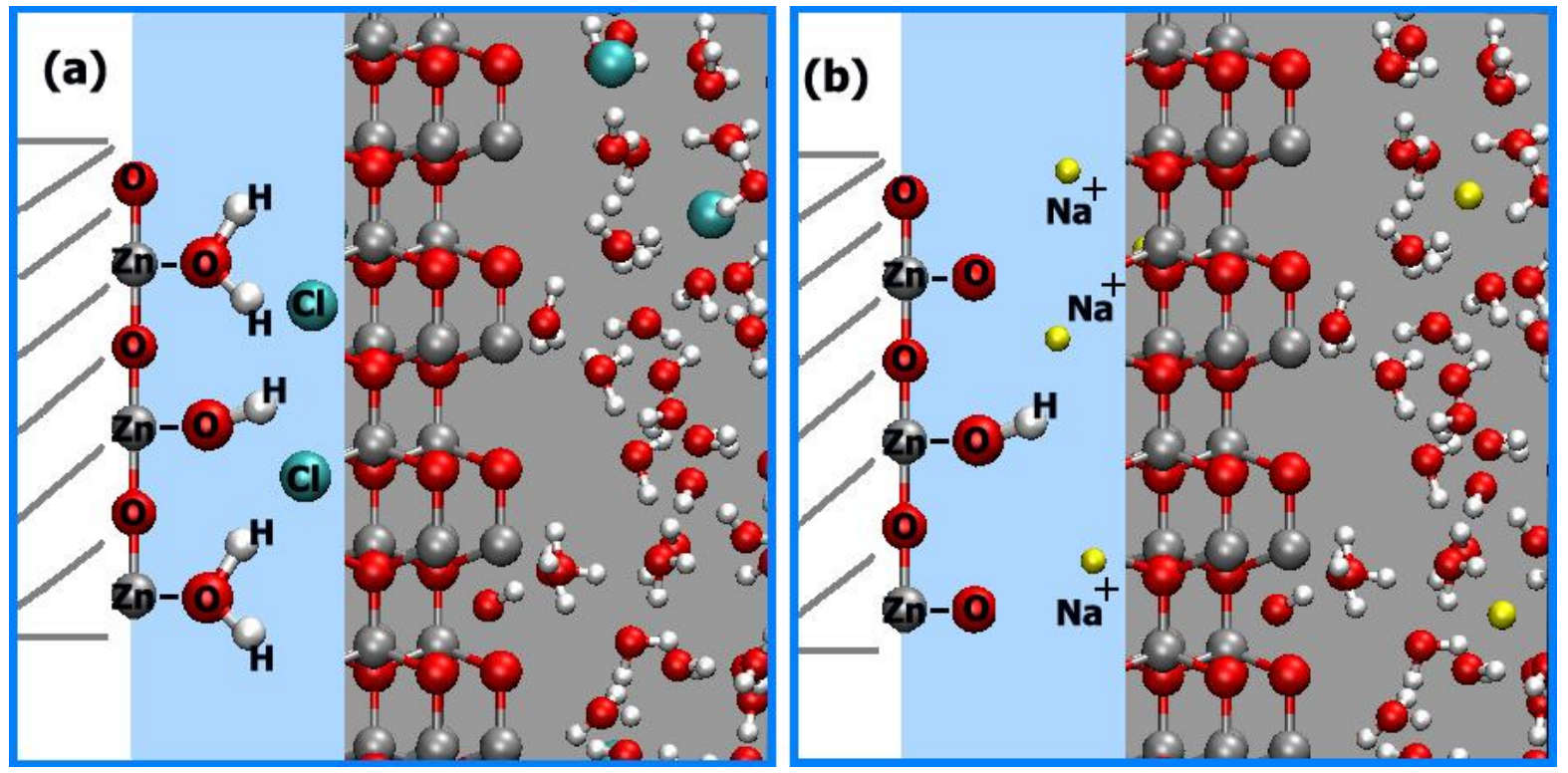

The surface charges are generated by primary adsorption and by chemisorption of $\mathrm{Cl}^{-}$. This process does not involve transport of $\mathrm{Na}^{+}$or $\mathrm{Cl}^{-}$ions into the solid (except in dislocations and then not as the rate-determining step). Proportionality of the reaction rate with the free electron concentration near the surface requires proportionality with band bending. The surface charge transferred at any $\mathrm{pH}$ by primary adsorption and chemisorption to the $\mathrm{ZnO}$ can be calculated from the reduced surface potential in the solid due to primary adsorption and chemisorption of $\mathrm{Cl}^{-}$ions. The surface charges are negative at all $\mathrm{pH}$ values, since all surface potential values are positive. This relationship can be understood by the following mechanisms [77]:

(a) At $\mathrm{pH}<9$ : On the first contact of $\mathrm{ZnO}$ with the aqueous solution, adsorption of $\mathrm{H}^{+}$on $\equiv \mathrm{ZnOH}$ groups and chemisorption of $\mathrm{Cl}^{-}$on $\equiv \mathrm{Zn}$ ions near the surface takes place. Of the charges transferred to the $\mathrm{ZnO}$ by these processes, only the negative charges imparted by $\mathrm{Cl}^{-}$ chemisorption are mobile ( $\mathrm{ZnO}$ is an electronic semiconductor). These charges thus distribute themselves over the surface region (Figure 19a).

(b) At $\mathrm{pH}>$ 9: On the first contact of $\mathrm{ZnO}$ with the aqueous solution, $\equiv \mathrm{ZnOH}$ groups combine with $\mathrm{OH}^{-}$ions, forming $\equiv \mathrm{ZnO}^{-}$. Again, the negative charge imparted by this process to the $\mathrm{ZnO}$ forms a space charge region (Figure 19b).

In terms of solid state chemistry, $\equiv \mathrm{ZnCl}^{-}$and $\equiv \mathrm{ZnO}^{-}$groups form surface states whose energy levels should be situated as depicted in Figure 20 at A and B, respectively. Thus, in all cases, an 
accumulation layer is formed at the surface of the $\mathrm{ZnO}$. In spite of the fact that free electrons at the surface are consumed by the reaction with $\mathrm{H}^{+}$at $\mathrm{pH}<9$, there remains an accumulation layer throughout the conditions investigated.

Figure 19. Schematic representation of the charges transferred to the $\mathrm{ZnO}$ by primary adsorption and chemisorption: (a) at $\mathrm{pH}<8.9$, (b) at $\mathrm{pH}>8.9$.

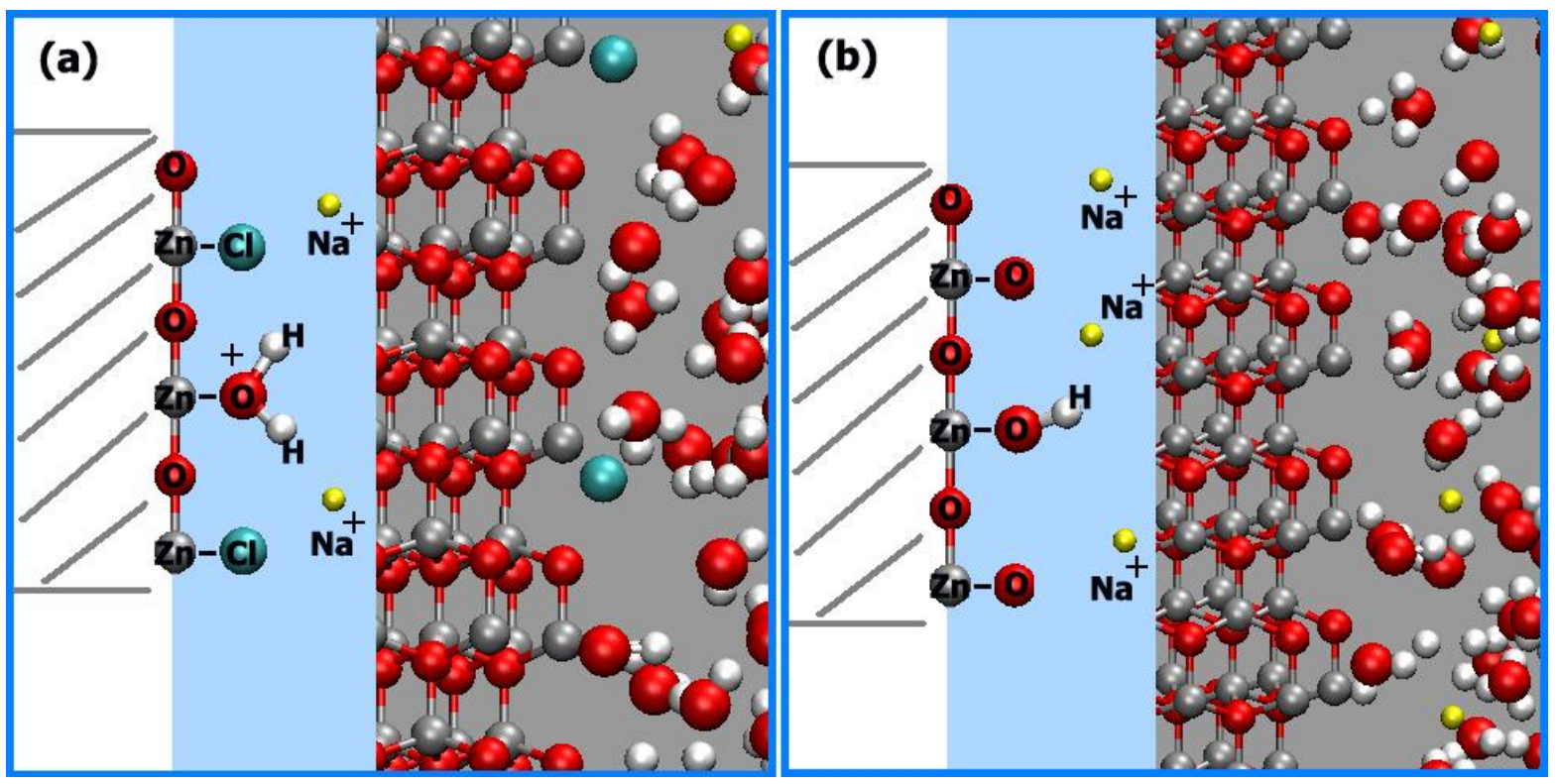

Figure 20. Schematic representation to the situation of the energy levels $\mathrm{ZnO}$ and surface states levels for $\equiv \mathrm{ZnCl}^{-}$and $\equiv \mathrm{ZnO}^{-}$groups which are labels as $\mathrm{A}$ and $\mathrm{B}$, respectively.

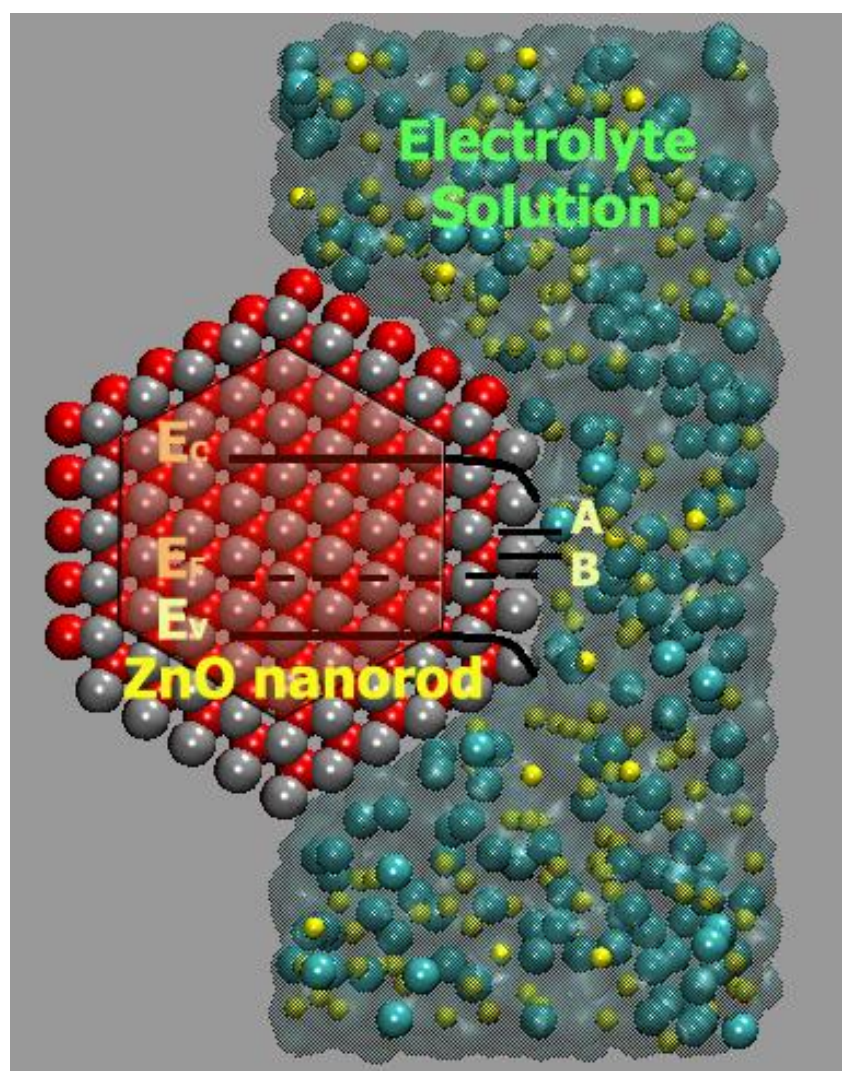


7.2.1. Adsorption of Water on the $(0001)-Z n$ and $(000 \overline{1})-O$ Surfaces

$\mathrm{ZnO}$ crystallizes in the wurtzite structure, which does not have a center of inversion. Consequently, when the crystal is cleaved normal to the c axis in a manner that breaks the fewest interatomic bonds, two different polar surfaces are formed on opposite sides of the crystal. Each of these surfaces has only one type of ion. Thus, opposing surfaces bear an opposite charge on their outermost planes. The ideal polar surfaces are called (0001) $-\mathrm{Zn}$ when the $\mathrm{Zn}$ cation is present at the surface and $(000 \overline{1})-O$ when the $O$ anion comprises the outermost layer. These polar $\mathrm{ZnO}$ surfaces are only stable if the $(000 \overline{1})-O$ face is less negative than, and the (0001) $Z n$ face is less positive than the formal bulk oxidation state by a factor of $R_{1} /\left(R_{1}+R_{2}\right)=1 / 4$, where $R_{1}=0.61 A$ and $R_{2}=1.99 A$. This charge redistribution may be explained by a decrease in the ionic charge of the surface ions, from \pm 2 to $\pm 3 / 2$, which may be considered an electron transfer from the $\mathrm{O}$-face to the $\mathrm{Zn}$-face. As a result, partially occupied surface bands will appear with a $3 / 4$ filled O-2p band at $(000 \overline{1})-O$ and a $1 / 4$ filled $\mathrm{Zn}-4 \mathrm{~s}$ band at the (0001) $-\mathrm{Zn}$ surface. This phenomenon is referred to as intrinsic state compensation [78] or as metallization of the polar surfaces [79].

Figure 21. Schematic diagram of the high-symmetry adsorption sites on the two polar surfaces of $\mathrm{ZnO}$, (a) for zinc surface termination top and side view, (b) for oxygen surface termination top and side view.

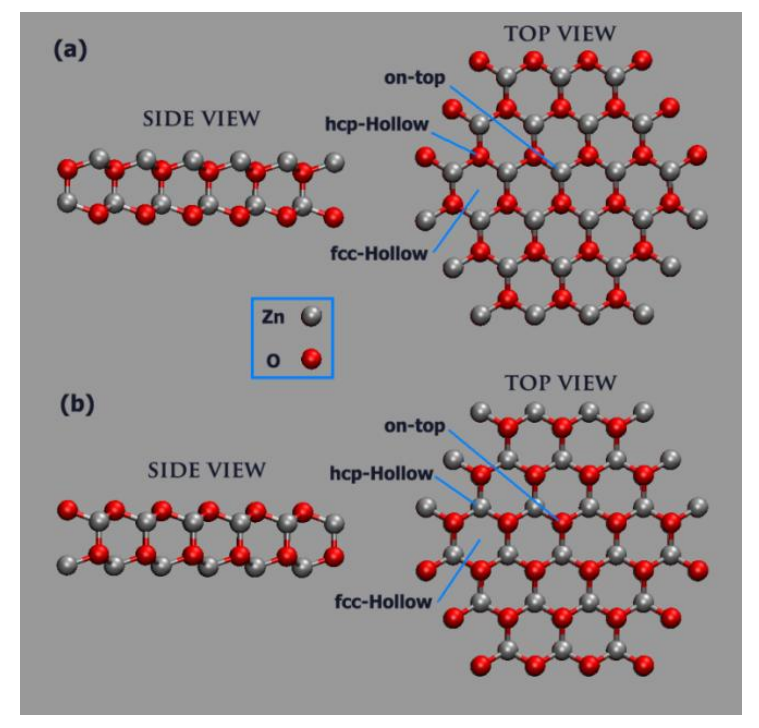

If the metallic state is present, it will depend on the dispersion of the partially occupied bands. In addition, the surface may reconstruct and undergo a distortion in which, for instance, at the $(000 \overline{1})-O$ surface, four surface atoms combine in such a way that an unoccupied $2 p$-band splits from the other eleven occupied 2p-bands and the surface become insulating again. On the other hand, the charge reduction of the surface layers may be take place by removing $1 / 4$ of the surface ions, creating vacancies. These vacancies may be ordered and may form a reconstruction, or they may be randomly distributed. When these $\mathrm{ZnO}$ polar surfaces come into contact with an electrolyte, the water molecules may dissociate and protons $\left(\mathrm{H}^{+}\right)$and hydroxyl groups $(\mathrm{OH})$ could adsorb, respectively, on every second $\mathrm{O}$ and $\mathrm{Zn}$ surface ion. The adsorption of these charged species would reduce the formal oxidation state of 
the surface ions. The adsorption sites of the dissociating water $\left(\mathrm{OH}^{-}\right.$and $\left.\mathrm{H}^{+}\right)$on the polar surface are on-top positions, hcp-hollow site positions above atoms in the second surface layer, and a fcc-hollow site with no atoms beneath (see Figure 21) [80,81].

\subsubsection{Adsorption of Water on the $(10 \overline{1} 0)-\mathrm{ZnO}$ Surfaces}

The nonpolar $\mathrm{ZnO}$ (10 10) surface is electrostatically stable. This wurtzite-type surface consists of layers containing slightly tilted $\mathrm{ZnO}$ dimers, which are formed by three-fold coordinated $\mathrm{Zn}$ and $\mathrm{O}$ ions. These $\mathrm{ZnO}$ dimers assemble to form characteristic rows separated by trenches (see Figure 22). For the adsorption of water on this surface, one would expect that the oxygen atoms of the water molecules bind strongly to the coordinatively unsaturated $\mathrm{Zn}$ ions on the surface. This strong binding is due to a lock and key type interaction between the water molecules and the $\mathrm{ZnO}$ surface. The water molecules are stabilized by three different types of attractive interactions to both the substrate and neighboring adsorbate molecules. 1) The $\mathrm{O}$ atoms of the water molecules occupy the $\mathrm{O}$ sites of a hypothetical next $\mathrm{ZnO}$ layer on the $\mathrm{ZnO}(10 \overline{10})$ surface so that the surface $\mathrm{Zn}$ ions regain their four-fold tetrahedral coordination as in the underlying bulk, which leads to a strong $\mathrm{Zn}-\mathrm{O}$ and thus $\mathrm{ZnO} / \mathrm{H}_{2} \mathrm{O}$ bonding. 2) One of the $\mathrm{H}$ atoms forms a hydrogen bond across the $\mathrm{ZnO}$ trench of the surface to a neighboring substrate $\mathrm{O}$ atom. 3) In the case of a convergent monolayer, a water-water hydrogen bond to a neighboring adwater is formed by the second $\mathrm{H}$ atom [82-84].

Figure 22. Side and top view of a clean and ideal $\mathrm{ZnO}\left(101^{\circ} 0\right)$ surface.

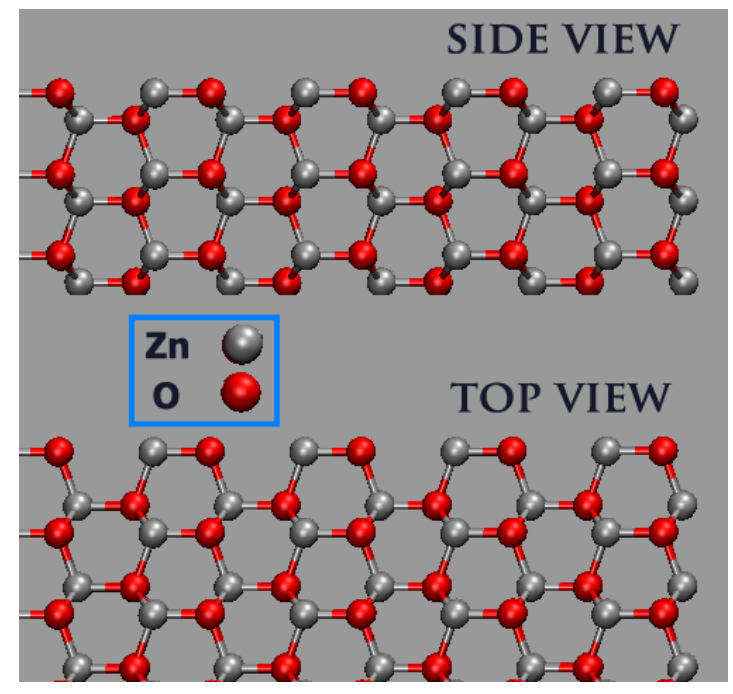

\section{Conclusions and Perspectives}

$\mathrm{ZnO}$ semiconductors have a range of unique properties, including their electronic properties and their size (in case of nanorods). The combination of these two important properties has driven extensive investigations in the last few years into their use in electrochemical devices, such as $\mathrm{pH}$ sensors. The application of $\mathrm{ZnO}$ nanorods as proton-sensitive electronic elements opens new challenges. In such applications, the size of the nanorods is the most important feature, not just in terms of their nanoscale diameters but also because their length is considerably greater than their diameter. This review highlights preliminary investigations of the $\mathrm{ZnO} /$ electrolyte interface. However, 
despite these gains, there are still tremendous opportunities and significant challenges to be solved. With regard to $\mathrm{pH}$ sensors, questions remain as to how commercializable devices can be made predictably and cheaply. The challenges of processing nanorods easily and integrating them with electronic devices in a simple manner are just beginning to be addressed. Using $\mathrm{ZnO}$ nanorods, it may be possible to make the ultimate nanoscale $\mathrm{pH}$ sensor, a single electronic element capable of single-ion recognition. Many of the challenges involving nanorods in bioelectronics also exist for applications where nanorods are to be integrated with living biological systems for use as intracellular $\mathrm{pH}$ sensors or ion-selective sensors.

\section{References and Notes}

1. Kittel, C. Introduction to Solid State Physics, 7th ed.; John Wiley \& Sons, Inc.: New York, NY, USA, 1996; pp. 244-255.

2. Sze, S.M.; Ng, K.K. Physics of Semiconductor Devices, 3rd ed.; John Wiley \& Sons, Inc.: Hoboken, NJ, USA, 2007; pp. 12-30.

3. Gerischer, H. Semiconductor electrode reactions. In Advances in Electrochemistry and Electrochemical Engineering: Electrochemistry, 1st ed.; Delahay, P., Tobias, C., Eds.; Interscience (Wiley): New York, NY, USA, 1961; Volume 1, pp. 139-232.

4. Bard, A.J. Photoelectrochemistry and heterogeneous photo-catalysis at semiconductors. $J$. Photochem. 1979, 10, 59-75.

5. Gerischer, H. Semiconductor electrochemistry. In Physical Chemistry: An Advanced Treatise, 1st ed.; Eyring, H., Henderson, D., Jost, W., Eds.; Academic Press: New York, NY, USA, 1970; Volume 9A, pp. 463-542.

6. Gerischer, H.Z. Uber den ablauf von redoxreaktionen an metallen und an halbleitern I: allgemeines zum elecktronenubergang zwischen einem festkorper und einem redoxelektrolyten. $Z$. Phys. Chem. (Frankfurt) 1960, 26, 223-247.

7. Gerischer, H.Z. Uber den ablauf von redoxreaktionen an metallen und an halbleitern. Z. Phys. Chem. (Frankfurt) 1961, 27, 48-79.

8. Nozik, A.J. Photoelectrochemistry: applications to solar energy conversion. Annu. Rev. Phys. Chem. 1978, 29, 189-222.

9. Memming, R. Processes at semiconductor electrodes. In Comprehensive Treatise of Electrochemistry, 1st ed.; Conway, B.E., Bockris, J.O’M., Yeager, E., Khan, S.U.M., White, R.E., Eds.; Plenum Press: New York, NY, USA, 1983; Volume 7, pp. 529-533.

10. Gerischer, H.Z. Uber den ablauf von redoxreaktionen an metallen und an halbleitern II: metallelektroden. Z. Phys. Chem. (Frankfurt) 1960, 26, 325-338.

11. Gerischer, H. Principles of electrochemistry. In The CRC Handbook of Solid State Electrochemistry, 1st ed.; Gellings, P.J., Bouwmeester, H.J.M., Eds.; CRC Press, Inc.: Boca Raton, FL, USA, 1997, pp. 30-50.

12. Gerischer, H. Electrochemical photo and solar cells-principles and some experiments. $J$. Electroanal. Chem. Interfacial Electrochem. 1975, 58, 263-274.

13. Gerischer, H.; Tributsch, H. Elektrochemische untersuchungen zur spektralen sensibilisierung von ZnO-einkristallen. Ber. Bunsenges. Phys. Chem. 1968, 72, 437-445. 
14. Cop, A.; Kovacevic, D.; Dragic, T.; and Kallay, N. Evaluation of equilibrium parameters characterizingmetal oxide/electrolyte solution interface. Colloids and Surface A: Physicochem. Eng. Aspects 2003, 230, 159-165.

15. Trimbos, H.F.A.; Stein, H.N. The $\mathrm{ZnO}$ /aqueous solution interface I: capacity of the double layer. J. Colloid Interface Sci. 1988, 77, 386-396.

16. Davis, J.A.; James, R.O.; and Leckie, J.O. Surface ionization and complexation at the oxide/water interface I: computation of electrical double layer properties in simple electrolytes. J. Colloid Interface Sci. 1978, 63, 480-499.

17. Healy, T.W.; Jellett, V.R. Adsorption-coagulation reactions of Zn II: Hydrolyzed species at the zinc oxide-water interface. J. Colloid Interface Sci. 1967, 24, 41-46.

18. Yates, D.E.; Levine, S.; Healy, T.W. Site-binding model of the electrical double layer at the oxide/water interface. J. Chem. Soc. Faraday Trans. I 1974, 70, 1807-1818.

19. Sprycha, R. Surface charge and adsorption of background electrolyte ions at anatase/electrolyte interface. J. Colloid Interface Sci. 1984, 102, 173-185.

20. Hames, R.O.; Davis, J.A.; Leckie, J.O. Computer simulation of the conductormetric and potentiometric titrations of the surface groups on ionizable latexes. J. Colloid Interface Sci. 1978, 65, 331-344.

21. Bootsma, G.A.; De Rooij, N.F.; Van Silfhout, A. The solid/liquid interface. Sen. Actuat. 1981, 1, 111-136.

22. Green, M. Electrochemistry of the semiconductor-electrolyte electrode I: the electrical double layer. J. Chem. Phys. 1959, 31, 200-203.

23. Tan, M.X.; Laibinis, P.E.; Nguyen, S.T.; Kesselman, J.M.; Stanton, C.E.; Lewis, N.S. Principles and applications of semiconductor photoelectrochemistry. In Progress in Inorganic Chemistry; Karlin, K.D., Ed.; John Wiley \& Sons: New York, NY, USA, 1994; Volume 41, pp. 21-144.

24. Gerischer, H. The impact of semiconductors on the concepts of electrochemistry. Electrochim. Acta 1990, 35, 1677-1699.

25. Piasecki, W. The influence of surface potential on quantities measuring for metal oxide/electrolyte solution interface: theoretical study based on 1-pK and 2-pK surface charging models. Phys. Chem. Chem. Phys. 2003, 5, 713-719.

26. Dewald, J.F. The charge distribution at the zinc oxide-electrolyte interface. J. Phys. Chem. Solids 1960, 14, 155-161.

27. Nozik, A.J.; Memming, R. Physical chemistry of semiconductor liquid interface. J. Phys. Chem. 1996, 100, 13061-13078.

28. Morrison, S.R. The Chemical Physics of Surfaces; Plenum Publishing Corporation: New York, NY, USA, 1990; pp. 54-293.

29. Morrison, S.R. Electrochemistry at Semiconductor and Oxidized Metal Electrodes; Plenum Press: New York, NY, USA, 1980.

30. Pleskowr, Y.V.; Gurevich, Y.Y. Semiconductor Photoelectrochemistry; Consultants Bureau: New York, NY, USA, 1986.

31. Lewis, N.S. Progress in understanding electron transfer reactions at semiconductor/liquid interfaces. J. Phys. Chem. 1998, 102, 4843-4855. 
32. Licht, S. Semiconductor electrodes and photoelectrochemistry. In Encyclopedia of Electrochemistry; Bard, A.J.; Stratmann, M., Eds.; Wiley-VCH Verlag, Weinheim, Germany, 2002; Volume 6.

33. Blok, L.; De Bruyn, P.L. The ionic double layer at the $\mathrm{ZnO} /$ solution interface III: comparison of calculated and experimental differential capacities. J. Colloid Interface Sci. 1970, 32, 533-538.

34. Friedmann, J.; Fruhwirth, O.; Herzog, G.W. Capacitances and losses of $\mathrm{ZnO} /$ Borax electrolyte and corroding Zn/Borax electrolyte contacts. Surf. Technol. 1978, 6, 469-478.

35. Logtenberg, E.H.P.; Stein, H.N. Surface sharge and coagulation of aqueous ZnO dispersions. $J$. Colloid Interface Sci. 1986, 109, 190-200.

36. Schubert, E.F.; Kuo, J.M.; Kopf, R.F.; Jordan, A.S. Fermi-level-pinning-induced impurity redistribution in semiconductors during epitaxial growth. Phys. Rev. B 1990, 42, 1364-1368.

37. Gabouze, N.; Fotouhi, B.; Gorochov, O.; Cachet, H.; Yao, N.A. Flatband potential shift of n-type GaAs in $\mathrm{CH}_{3} \mathrm{CN}$ containing different redox reagents. J. Electroanal. Chem. 1987, 237, 289-293.

38. Schmuki, P.; Bohni, H.; Bardwell, J. In situ characterization of anodic silicon oxide films by AC impedance measurements. J. Electrochem. Soc. 1995, 142, 1705-1712.

39. Bard, A.J.; Faulkner, L.R. Electrochemical Methods, 2nd ed.; John Wiley \& Sons, Inc.: New York, NY, USA, 2001.

40. Zoski, C.G. Handbook of Electrochemistry, 1st ed.; Elsevier: Amsterdam, The Netherlands, 2007; pp. 329-390.

41. Hamann, T.W.; Gstrein, F.; Brunschwing, B.S.; Lewis, N.S. Measurement of the driving force dependence of interfacial charge transfer rate constants in response to $\mathrm{pH}$ charges at $\mathrm{n}-\mathrm{ZnO} / \mathrm{H}_{2} \mathrm{O}$ interfaces. Chem. Phys. 2006, 326, 15-23.

42. Arutyunyan, V.M. Physical properties of the semiconductor-electrolyte interface. Sov. Phys. Usp. 1989, 32, 521-542.

43. Kovacs, I.K.; Horvai, G. Possibilities of chemical sensing at the semiconductor/electrolyte interface. Sens. Actuat. B 1994, 18-19, 315-320.

44. Pettinger, B.; Schöppel, H.R.; Yokoyama, T.; Gerischer, H. Tunneling processes at highly doped $\mathrm{ZnO}$ electrode in aqueous electrolytes II: electron exchange with the valence band. Ber. Bunsenges. Phys. Chem. 1974, 78, 1024-1030.

45. Uosaki, K.; Kita, H. Effects of the Helmholtz layer capacitance on the potential distribution at semiconductor/electrolyte interface and the linearity of the Mott-Schottky plot. J. Electrochem. Soc. 1983, 130, 895-897.

46. De Gryse, R.; Gomes, W.P.; Cardon, F.; Vennik, J. On the interpretation of Mott-Schottky plots determined at semiconductor/electrolyte systems. J. Electrochem. Soc. 1975, 122, 711-712.

47. Parthasarathy, M.; Ramgir, N.S.; Sathe, B.R.; Mulla, I.S.; Pillai, V.K. Surface-state-mediated electron transfer at nanostructured $\mathrm{ZnO}$ multipod/electrolyte interfaces. J. Phys. Chem. C 2007, $111,13092-13102$.

48. Tornow, J.; Schwarzberg, K. Electrical response of wet chemically grown ZnO nanorods for photovoltaic application. Mater. Res. Soc. Symp. Proc. 2006, 974, 0974-CC10-27.

49. Mora-Sero, I.; Fabregat-Santiago, F.; Denier, B.; Bisquert, J. Determination of carrier density of $\mathrm{ZnO}$ nanowires by electrochemical technique. Appl. Phys. Lett. 2006, 89, 203117. 
50. Makarova, M.V.; Macunova, K.; Krtil, P. The effect of cationic disorder on the optical and electrochemical behavior of nanocrystalline $\mathrm{ZnO}$ prepared from precursors. J. Solid State Electrochem. 2006, 10, 320-328.

51. Qu, F.; Morais, P.C. An oxide semiconductor nanoparticle in an aqueous medium: a surface charge density investigation. J. Phys. Chem. B 2000, 104, 5232-5236.

52. Redmond, G.; O’Keeffe, A.; Burgess, C.; MacHale, C.; Fitzmaurice, D. Spectroscopic determination of the flatband potential of transparent nanocrystalline $\mathrm{ZnO}$ films. J. Phys. Chem. 1993, 97, 11081-11086.

53. Schmidt-Mende, L.; MacManus-Driscoll, J.L. ZnO nanostructures defects and devices. Mater. Today 2007, 10, 40-48.

54. Adamson, A.W.; Gast, A.P. Physical Chemistry of Surfaces, 6th ed.; John Wiley \& Sons, Inc.: New York, NY, USA, 1997.

55. Somorjai, G.A. Introduction to Surface Chemistry and Catalysis; John Wiley \& Sons: New York, NY, USA, 1994.

56. Oekermann, T.; Schlettwein, D.; Jaeger, N.I. Role of surface states and adsorbates in time-resolved photocurrent measurements and photovoltage generation at phthalocyaninatozic II-photocathodes. J. Electroanal. Chem. 1999, 462, 222-234.

57. Van Meirhaeghe, R.L.; Cardon, F.; Gomes, W.P. A quantitative expression for partial Fermi level pinning at semiconductor/redox electrolyte interfaces. J. Electroanal. Chem. 1985, 188, 287-291.

58. Bard, A.J.; Bocarsly, A.B.; Fan, F-R.F.; Ealton, E.G.; Wrighton, M.S. The concept of Fermi level pinning at semiconductor/liquid junctions: consequences for energy conversion efficiency and selection of solution redox couples in solar devices. J. Am. Chem. Soc. 1980, 102, 3671-3677.

59. Bardeen, J. Surface states and rectification at a metal semi-conductor contact. Phys. Rev. 1947, 71, 717-727.

60. Mead, C.A.; Spitzer, W.G. Fermi level position at metal-semiconductor interfaces. Phys. Rev. A 1964, 134, A713-A716.

61. McGill, T.C. Phenomenology of metal-semiconductor electrical barriers. J. Vac. Sci. Technol. 1974, 11, 935-942.

62. Kurtin, S.; McGill, T.C.; Mead, C.A. Fundamental transition in the electronic nature of solids. Phys. Rev. Lett. 1969, 22, 1433-1436.

63. Rajeshwar, K. Fundamentals of semiconductor electrochemistry and photoelectrochemistry. In Encyclopedia of Electrochemistry; Licht, S., Ed.; Wiley-VCH: Weinheim, Germany, 2001; pp. 3-53.

64. Liao, Z.; Liu, K.; Zhang, J.; Xu, J.; Yu, D. Effect of surface states on electron transport in individual $\mathrm{ZnO}$ nanowires. Phys. Lett. A 2007, 367, 207-210.

65. Jones, F.; Leonard, F.; Talin, A.A. Electrical conduction and photoluminescence properties of solution-grown $\mathrm{ZnO}$ nanowires. J. Appl. Phys. 2007, 102, 014305.

66. Green, M. In Modern Aspects of Electrochemistry; Bockris, J.O’M., Ed.; Plenum: New York, NY, USA, 1959; Volume 2, pp. 356-381.

67. Tamm, I.E. A possible kind of electron binding on crystal surfaces. Z. Phys. 1932, 76, 76849-76850.

68. Shockley, W. On the surface states associated with a periodic potential. Phys. Rev. 1939, 56, 317-323. 
69. Gerischer, H. Semiconductor electrochemistry. In Physical Chemistry: An Advanced Treatise; Eyring, H., Henderson, D., Jost, W., Eds.; Academic Press: New York, NY, USA, 1970; Volume IXA, pp. 463-542.

70. Greene, L.E.; Law, M.; Goldberger, J.; Kim, F.; Johnson, J.C.; Zhang, Y.; Saykally, R.J.; Yang, P. Low-temperature wafer-scale production of $\mathrm{ZnO}$ nanowire arrays. Angew. Chem. Int. Ed. 2003, 42, 3031-3034.

71. Vayssieres, L.; Keis, K.; Lindquist, S-E.; Hagfeldt, A. Purpose-build anisotropic metal oxide material: 3D highly oriented microrod. J. Phys. Chem. B 2001, 105, 3350-3352.

72. Li, Q.; Kumar, V.; Li, Y.; Zhang, H.; Marks, T.J.; Chang, R.P.H. Fabrication of ZnO nanorods and nanotubes in aqueous solutions. Chem. Mater. 2005, 17, 1001-1006.

73. Al-Hilli, S.; Öst, A.; Strålfors, P.; Willander, M. ZnO nanorods as an intracellular sensor for $\mathrm{pH}$ measurements. J. Appl. Phys. 2007, 102, 084304.

74. Parks, G.A.; De Bruyn, P.L. The zero point of charge of oxides. J. Phys. Chem. 1960, 66, 967-973.

75. Blok, L.; De Bruyn, P.L. The ionic double layer at the $\mathrm{ZnO}$ solution interface II: composition model of the surface. J. Colloid Interface Sci. 1970, 32, 527-532.

76. Blok, L.; De Bruyn, P.L. The ionic double layer at the $\mathrm{ZnO}$ solution interface I: the experimental point of zero charge. J. Colloid Interface Sci. 1970, 32, 518-526.

77. Trimbos, H.F.A.; Stein, H.N. The $\mathrm{ZnO}$ /aqueous solution interface II: mechanism of the slow process. J. Colloid Interface Sci. 1980, 77, 397-407.

78. Nosker, R.W.; Mark, P.; Levine, J.D. Polar surfaces of wurtzite and zincblende lattices. Surf. Sci. 1970, 19, 291-317.

79. Wander, A.; Schedin, F.; Steadman, P.; Norris, A.; McGrath, R.; Turner, T.S.; Thornton, G.; Harrison, N.M. Stability of polar oxide surfaces. Phys. Rev. Lett. 2001, 86, 3811-3814.

80. Meyer, B. First principle study of the polar O-terminated $\mathrm{ZnO}$ surface in thermodynamic equilibrium with oxygen and hydrogen. Phys. Rev. B 2004, 69, 045416.

81. Wander, A.; Harrison, N.M. The stability of polar oxide surfaces: The interaction of $\mathrm{H}_{2} \mathrm{O}$ with $\mathrm{ZnO}(0001)$ and $\mathrm{ZnO}\left(0001^{\circ}\right)$. J. Chem. Phys. 2001, 115, 2312-2316.

82. Meyer, B.; Marx, D.; Dulub, O.; Diebold, U.; Kunat, M.; Langenberg, D.; Woll, C. Partial dissociation of water leads to stable superstructure on the surface of zinc oxide. Angew. Chem. Int. Ed. 2004, 43, 6642-6645.

83. Dulub, O.; Meyer, B.; Diebold, U. Observation of the dynamical change in a water monolayer adsorbed on a ZnO surface. Phys. Rev. Lett. 2005, 95, 136101.

84. Yan, Y.; Al-Jassim, M.M. Structure and energetic of water adsorbed on the $\mathrm{ZnO}$ (1010) surface. Phys. Rev. B 2005, 72, 235406.

(C) 2009 by the authors; licensee Molecular Diversity Preservation International, Basel, Switzerland. This article is an open-access article distributed under the terms and conditions of the Creative Commons Attribution license (http://creativecommons.org/licenses/by/3.0/). 